NBER WORKING PAPER SERIES

MONEY OR GRIT? DETERMINANTS OF MISMATCH

\author{
Russell Cooper \\ Working Paper 22734 \\ http://www.nber.org/papers/w22734 \\ NATIONAL BUREAU OF ECONOMIC RESEARCH \\ 1050 Massachusetts Avenue \\ Cambridge, MA 02138 \\ October 2016, Revised April 2018
}

The views expressed herein are those of the authors and do not necessarily reflect the views of the National Bureau of Economic Research.

NBER working papers are circulated for discussion and comment purposes. They have not been peer-reviewed or been subject to the review by the NBER Board of Directors that accompanies official NBER publications.

(C) 2016 by Russell Cooper. All rights reserved. Short sections of text, not to exceed two paragraphs, may be quoted without explicit permission provided that full credit, including () notice, is given to the source. 
Money or Grit? Determinants of MisMatch

Russell Cooper

NBER Working Paper No. 22734

October 2016, Revised April 2018

JEL No. E21,E24,I21,I23,I26

\begin{abstract}
$\underline{\text { ABSTRACT }}$
This paper studies the determinants of mismatch in educational attainment. Mismatch arises when high ability individuals do not obtain a college degree and/or low ability individuals do. Using data from the NLSY97 survey, the paper estimates a structural model of education choice that matches the moments of mismatch, college attainment and labor market outcomes. The analysis conditions on gender, race and socio-economic status. Ignoring the role of parents, mismatch is explained by differences in tastes for education and the presence of occasionally binding borrowing constraints. But parents matter. This channel operates through both the attitudes and ability of offspring. Once these links between parents and children are taken into account, the influence of borrowing constraints disappears. Mismatch reflects variations in tastes as well as noise in test scores, the underlying measure of ability. The paper also presents a decomposition of the college wage premium into the returns to schooling and the selection into higher education. The analysis highlights the power of selection into higher education as an explanation of the college wage premium by gender, race and socio-economic status.
\end{abstract}

\author{
Russell Cooper \\ Department of Economics \\ The Pennsylvania State University \\ 611 Kern \\ State College, PA 16802 \\ and NBER \\ russellcoop@gmail.com
}




\title{
Money or Grit? Determinants of MisMatch*
}

\author{
Russell Cooper ${ }^{\dagger}$
}

April 21, 2018

\begin{abstract}
This paper studies the determinants of mismatch in educational attainment. Mismatch arises when high ability individuals do not obtain a college degree and/or low ability individuals do. Using data from the NLSY97 survey, the paper estimates a structural model of education choice that matches the moments of mismatch, college attainment and labor market outcomes. The analysis conditions on gender, race and socio-economic status. Ignoring the role of parents, mismatch is explained by differences in tastes for education and the presence of occasionally binding borrowing constraints. But parents matter. This channel operates through both the attitudes and ability of offspring. Once these links between parents and children are taken into account, the influence of borrowing constraints disappears. Mismatch reflects variations in tastes as well as noise in test scores, the underlying measure of ability. The paper also presents a decomposition of the college wage premium into the returns to schooling and the selection into higher education. The analysis highlights the power of selection into higher education as an explanation of the college wage premium by gender, race and socio-economic status.
\end{abstract}

JEL classification: I26, J24

\section{$1 \quad$ Introduction}

This paper studies mismatch in the allocation of individuals to educational attainment. This is a topic of considerable interest as it is central to the debate on both the efficiency and equity of the educational system. Mismatch is often viewed as a signal of misallocation in the assignment of individuals to education outcomes.

Mismatch in educational attainment can arise in essentially two forms. In the case of an under-match, a relatively high ability individual does not go to college. Under-match is frequently associated with imperfect capital markets so that high ability individuals with limited resources find a college education too expensive. Alternatively, it might be that the individual is simply not motivated nor otherwise equipped for the rigors of college life. These competing explanations are summarized as "money" or "grit", though as we shall see, the non-financial factors that influence the education choice may go well beyond determination alone.

\footnotetext{
* This paper began as joint work with Huacong Liu and I am very appreciative for her collaboration and contribution. I alone bear responsibility for any errors. I am grateful to Paul Grieco, Kala Krishna, Charles Murry and Mark Roberts as well as seminar participants at the Federal Reserve Bank of Philadelphia and NYUAD for comments on an earlier version of this paper. Research assistance from Mengli Sha and David Lander is much appreciated.

${ }^{\dagger}$ Department of Economics, the Pennsylvania State University and NBER, russellcoop@gmail.com
} 
In the alternative case of over-match, a relatively low ability individual obtains a college degree. This is not the consequence of capital market imperfections. But, as in the case of under-match, tastes might matter in the form of motivation and grit strong enough to compel a low ability individual through college.

This paper is about the magnitudes and determinants of mismatch. Bowen and Bok (1998) brought widespread attention to the significance of mismatch. There are now numerous studies of mismatch using US data, many follow the approach of Smith, Pender, and Howell (2013). Dillon and Smith (2013) study mismatch based on the National Longitudinal Survey of Youth from 1997 (hereafter NLSY97). They find evidence of both under- and over-match. Their analysis includes a measure of college quality so that mismatch also refers to the relationship between the ability of a student and the quality of college the student attends.

The approach and findings differ from the extant literature as it formulates a dynamic choice problem and uses that structure to estimate key parameters. ${ }^{1}$ An outgrowth of the estimation is a determination of the sources of mismatch. The estimation follows a simulated method of moments approach, where the mismatch rates are prominent features of the data that we match.

The estimation uses moments from the NLSY97. In addition to the measured under- and over-match rates, the moments include the individual's education choice as a function of their (ASVAB) test score as well as their labor market outcomes, also as a function of their test score. The moments are calculated, and thus the estimation is undertaken, for the whole sample as well as sub-groups distinguished by gender, race and socio-economic status $(\mathrm{SES}) .^{2}$

This data set figures prominently in the literature on mismatch and more generally in the discussion of the effects of borrowing constraints on educational attainment. As discussed in Belley and Lochner (2007a), capital market imperfections appear more prominent in the NLSY97 data compared to the NLSY79 data, as studied by Cameron and Heckman (2001) and Keane and Wolpin (2001). The paper returns to this debate both through an analysis of the role of borrowing constraints and more generally by linking family resources and background to educational attainment and mismatch.

The model allows for three sources of mismatch. First, borrowing constraints can create under-match. Second, variations across individuals in tastes for education can create both under- and over-match. Finally, the test score observed in the data, as described below, may itself be a noisy measure of ability. In this case, mismatch is simply measurement error.

For the baseline model without explicit parental influence, there are two initial findings. First, there is evidence of capital market frictions for the full sample as well as the groups distinguished by gender, race and SES. Second, taste shocks (grit) are important source of mismatch, noisy test scores are not.

The paper includes a section on robustness with respect to the measurement and model of ability. Following Heckman, Stixrud, and Urzua (2006), ability is allowed to have both cognitive and non-cognitive components. Each influence the education decision and each are reflected in compensation. This extension brings additional moments, reflecting the dependence of educational attainment and wages on two measures of ability into the analysis. There is some evidence of capital market frictions and, once again, a prominent role for taste shocks. The latter point is important since mismatch due to the exclusion of non-cognitive ability would be attributed to taste shocks in the

\footnotetext{
${ }^{1}$ Cooper and Liu (2016) undertakes a similar exercise looking at college attainment across countries.

${ }^{2}$ I appreciate the suggestion of Dubravka Ritter of the Federal Reserve Bank of Philadelphia to include the SES breakdown.
} 
baseline model.

The baseline model also provides a decomposition of the college wage premium. The return to education is estimated and the selection into college, determined by the choice problem of individual agents, is characterized.

It is natural to study the influence of the families in generating these results. One might conjecture that the estimated borrowing constraint provides a channel through which family resources influence education choice. But, as emphasized in Cameron and Heckman (2001), family income may be highly correlated with other dimensions of family life that impact educational decisions through tastes and/or ability rather than through the budget constraint.

Accordingly, the analysis expands to allow either family income and/or mother's education to influence the education choice. The specification in which the mother's education proxies for tastes fits the moments very closely. A specification which links mother's education to the child's ability produces a close fit as well.

As in Cameron and Heckman (2001), it seems that family influence through tastes and/or ability is more powerful than simply shifting a budget constraint. In these model with an active role for parent's education, mismatch arises largely from taste shocks as there is no evidence of binding borrowing constraints. For this specification, noise in the test score contributes as well to explain mismatch.

\section{Evidence of MisMatch}

This section presents the data and evidence of mismatch. The moments presented here are subsequently used in the structural estimation.

\section{$2.1 \quad$ Data}

The data are drawn from the 1997 National Longitudinal Survey of Youth (NLSY97). ${ }^{3}$ The data include individuals born between 1980 and 1984. At the time of first interview in 1997, respondents' ages ranged from 12 to 18 . The respondents were 28 to 34 at the time of their round 16 interviews in 2013. Most respondents graduated high school and made their college choice between 1999 and 2002.

ASVAB is the measure of ability used in this study. Most NLSY97 respondents participated in the administration of the computer-adaptive form of the Armed Services Vocational Aptitude Battery (CAT-ASVAB) in 1997. The ASVAB test has 12 components, a subset of which including mathematical knowledge (MK), arithmetic reasoning (AR), word knowledge (WK), and paragraph comprehension (PC) is referred to as Armed Forces Qualification Test (AFQT). It has been demonstrated in the literature that AFQT is a good measure of ability and is statistically significant in predicting outcomes (see Cawley, Conneely, Heckman, and Vytlacil (1997) and Cawley, Heckman, and Vytlacil (2001)). The analysis categorizes individuals according to their AFQT score quartiles.

Educational attainment is dichotomous, indicating whether an individual has at least obtained a bachelor's degree or not in 2013, the latest round of interview. Individuals who have only obtained an Associate of Arts degrees are not counted as having college attainment.

\footnotetext{
${ }^{3}$ Further details on the variables used in this study are presented in the appendix. For details on the data set, see https://www . nlsinfo.org/content/cohorts/nlsy97. Education attainment and wages are taken from the 2013 wave and the ASVAB exam score is reported in the 1999 wave.
} 
Some of the analysis conditions on gender, race/ethnicity and SES status. The analysis focuses on two ethnic groups: blacks and whites (defined as non-black and non-hispanic). The determination of high and low SES is based on whether parent's income was above or below the sample median.

The following criteria were used to drop missing observations: negative test scores, negative wages, negative education and negative parents income. The resulting sample size was 2882 in total.

\subsection{Mismatch}

Motivated by Smith, Pender, and Howell (2013), consider a logistic regression to characterize education choice at the individual level:

$$
\operatorname{Pr}\left(e_{i}=1\right)=\frac{\exp ^{\alpha_{0}+\alpha_{1} a_{i}}}{1+\exp ^{\alpha_{0}+\alpha_{1} a_{i}}}
$$

where $a_{i}$ is the AFQT test score of individual $i$. Here $e_{i}=0$ signifies that an individual has no college degree and $e_{i}=1$ signifies college attainment and beyond. As the analysis proceeds additional covariates will be added to this basic regression.

Measures of under- and over-match rates come from this regression. A household is under-matched if it does not have a college degree but, through (1), the probability $e_{i}=1$ exceeds the 80 th percentile of the predicted values of individuals with college attainment. Likewise, a household is over-matched if it has attained a college degree but the predicted probability that $e_{i}=1$ is less than the 20 th percentile of those without a college degree. An attractive feature of this measure is that at an efficient allocation, where there is a critical level of ability for college attainment, there is neither over- nor under-match. ${ }^{4}$

Clearly, the $20 \%$ and $80 \%$ percentiles are arbitrary, mismatch measures can be calculated with other cut-off values as well. Despite this, these measures are informative. These same cut-offs are used in the structural estimation so that actual and simulated data are treated in a similar way.

Note that these measures are within a group: a low SES household is over-matched if he has a college degree but has a sufficiently low probability of college attainment compared to other low SES households. Section 6.2 considers other measures in which the over- and under-match rates are relative to the whole sample, not the group. Again, this is not an issue for estimation, just for interpretation.

\subsection{Moments}

The set of data moments for the baseline models is presented in Table 1. The first row combines the sample and subsequent rows break down by gender, race and SES status.

The first column indicates the college attainment rate, ranging from $48 \%$ for female to $30 \%$ for low SES households. The under- and over-match rates also vary substantially across the groups. The under-match rate is largest for the high SES group, at 4.4\%. For all groups, the under-match rate exceeds the over-match rate, particularly for females and low SES households. This is an important feature of the data that the estimated model will have to match.

\footnotetext{
${ }^{4}$ In a previous version of this paper, the comparison was with all predicted values rather than the 80th percentile of those with college attainment. With that approach, mismatch could arise in an efficient solution. See Cooper and Liu (2016) for further discussion of these alternative measures.
} 
Table 1: Data Moments

\begin{tabular}{c|ccccccc|c} 
& college & under-match & over-match & $\alpha_{0}$ & $\alpha_{1}$ & $\nu_{1}$ & $\nu_{2}$ & Obs. \\
\hline \hline all & 0.409 & 0.035 & 0.014 & -2.906 & 0.043 & 0.009 & 0.006 & 2882 \\
& & & & 0.117 & 0.002 & 0.001 & 0.001 & \\
male & 0.349 & 0.019 & 0.012 & -3.335 & 0.045 & 0.008 & 0.005 & 1509 \\
& & & & 0.176 & 0.003 & 0.001 & 0.001 & \\
female & 0.480 & 0.040 & 0.015 & -2.545 & 0.041 & 0.011 & 0.007 & 1373 \\
& & & & 0.162 & 0.003 & 0.001 & 0.001 & \\
white & 0.441 & 0.030 & 0.027 & -3.276 & 0.047 & 0.007 & 0.003 & 1761 \\
& & & & 0.181 & 0.003 & 0.001 & 0.001 & \\
black & 0.308 & 0.035 & 0.023 & -2.666 & 0.044 & 0.014 & 0.010 & 603 \\
& & & & 0.214 & 0.004 & 0.002 & 0.002 & \\
low SES & 0.300 & 0.029 & 0.015 & -3.157 & 0.041 & 0.009 & 0.006 & 1451 \\
& & & & 0.167 & 0.003 & 0.001 & 0.001 & \\
high SES & 0.502 & 0.044 & 0.038 & -2.502 & 0.041 & 0.008 & 0.006 & 1431 \\
& & & & 0.169 & 0.003 & 0.001 & 0.001 & \\
\hline
\end{tabular}

This table reports data moments from the NLSY97. "College" is the college attainment rate. The regression coefficients $\alpha_{0}$ and $\alpha_{1}$ are from (1). The predicted values from this regression are used to create the undermatch and over-match rates. The regression coefficients $\nu_{1}$ and $\nu_{2}$ are from (2) and (3) and characterize the response of wages to test scores. The last column indicates sample size. Standard errors are provided below regression coefficients.

The regression coefficients from $(1),\left(\alpha_{0}, \alpha_{1}\right)$, are included as moments. This provides an informative link between the test score and the educational choice.

A final piece of evidence used in the analysis is the dependence of compensation on the test score. This comes from a regression of the log of the real hourly wage on the test score, with and without including an educational attainment dummy as a covariate. Specifically, letting $i$ be an individual, the coefficients, $\nu_{1}$ and $\nu_{2}$ on the test score in Table 1 came from the following two regressions:

$$
E\left[\omega_{i} \mid \cdot\right]=\nu_{01}+\nu_{1} * \text { test }_{i}
$$

and

$$
E\left[\omega_{i} \mid \cdot\right]=\nu_{02}+\nu_{2} * \text { test }_{i}+\nu_{3} * e d_{i} .
$$

This set of moments is important as it disciplines the noise of the test score in predicting ability.

\section{Model}

This section outlines the household choice model, drawing on Cooper and Liu (2016). The focus is on the education choice and the influence of tastes, capital markets and information on that decision. The model is used as a basis for estimation.

The model is simplified to highlight the education decision. In particular, there is no uncertainty over income or periods of unemployment. Further, the household does not have a complicated portfolio decision. As studied, for example in Cooper and Zhu (2015), households who differ by educational attainment also differ in terms of asset market participation, portfolio composition and portfolio adjustment patterns. While of interest, none of the 
dimensions of household finance seemed crucial to the educational attainment decision.

The households are of different "types". The heterogeneity is along multiple dimensions including: (i) cognitive ability, (ii) taste for education and (iii) initial wealth. These factors all contribute to the education decision.

\subsection{LifeCycle}

To study education choice and mismatch, consider a simple life-cycle model of the household. The model is complex enough to capture the costs and benefits of the college choice, abstracting from other choices on the allocation of time between study and work as well as the decision to complete college.

The three phases of the lifecycle are illustrated in Figure 1. During the first $T^{s}$ periods of life, the individual can attend school and/or work. The second and third phases, of length $T^{e}$ and $T^{l}$, are both periods of work with compensation reflecting two features: the education decision made in the first phase and the role of experience. The role of experience interacts with the education decision. In this way, the education choice influences both the level of lifetime compensation and its pattern over time. Let $T=T^{s}+T^{e}+T^{l}$ be the total lifetime of the household.

Figure 1: Phases of Lifecycle

\begin{tabular}{lrrr} 
schooling & \multicolumn{2}{c}{ early work } & late work \\
\hline$T^{s}$ & $T^{s}+T^{e}$ & $T^{s}+T^{e}+T^{l}$
\end{tabular}

This figure shows the household's lifecycle.

\subsection{Perfect Capital Markets}

The household compares the utility flow from a college degree with the utility without college attainment. Initially assume that the household is able to borrow and lend in perfectly competitive capital markets at an interest factor of $R$. In this setting, the household ranks these options by comparing lifetime income, net of education costs. The only complicating factor is the presence of taste shocks in this choice.

For the analysis, let $e \in\{0, \bar{e}\}$ denote the education choice. Further, let $\theta$ denote the ability of the individual. ${ }^{5}$ Throughout we assume that $\theta$ is known to the agent.

The lifetime discounted present value of income for the individual is the sum of the discounted values from the three periods:

$$
Y(e, \theta)=Y^{s}(e)+\frac{Y^{e}(e, \theta)}{R^{T^{s}}}+\frac{Y^{l}(e, \theta)}{R^{T^{s}+T^{e}}},
$$

for $e \in\{0, \bar{e}\}$. Throughout this discussion, define $\tilde{R}^{x}=\frac{R^{x-1}}{\left(1+R+R^{2}+\ldots+R^{x-1}\right)}$ where $R$ is the real interest rate and $x$ is the length of the period of the flow that is being discounted.

The income flow during the school phase is given by:

$$
Y^{s}(e)=\frac{\omega_{1}(1-e)-p(e)}{\tilde{R}^{T^{s}}} .
$$

\footnotetext{
${ }^{5}$ At this point, $\theta$ is considered cognitive ability and thus reflected in the AFQT test. In section 7, we consider a model with non-cognitive ability as well.
} 
This expression allows both the income and the tuition paid in the education phase to depend on the choice of $e$.

The return to education depends on the agent's ability through labor earnings in the second and third phases of the lifecycle. Specifically, a household of ability $\theta$ that chooses education $e \in\{0, \bar{e}\}$ obtains labor income of $\omega_{j} H(e, \theta)$ for $j=1$ (early work) and $j=2$ (late work). $H(e, \theta)$ will be specified to create a complementarity between ability and education.

The discounted present value of income over the early work phase of life is:

$$
Y^{e}(e, \theta)=\frac{\omega_{1} H(e, \theta)}{\tilde{R}^{T^{e}}}
$$

for $e \in\{0, \bar{e}\}$ where $\tilde{R}^{T^{e}}$ discounts the flow of income during the middle phase back to the start of the early work period. Similarly, the discounted present value of income over the late work phase of life is:

$$
Y^{l}(e, \theta)=\frac{\omega_{2} H(e, \theta)}{\tilde{R}^{T^{l}}}
$$

for $e \in\{0, \bar{e}\}$ where $\tilde{R}^{T^{l}}$ discounts the flow of income during the final phase back to the start of the late work period. Both of these flows depend on ability, $\theta$, only if the agent attends college. Assume $\omega_{2} \geq \omega_{1}$ to allow for some experience effect on wages which, as noted above, interacts with education and ability.

\subsubsection{No College}

If the agent does not go to school, the discounted present value of net income during the school years is given by:

$$
Y^{s}(0, \theta)=\frac{\omega_{1}}{\tilde{R}^{T^{s}}}
$$

In this case there is no tuition charge and the individual works full time, earning a base wage of $\omega_{1}$. Note that the agent's ability $\theta$ does not factor into earnings during this period.

Further,

$$
Y^{e}(0, \theta)=\frac{\omega_{1}}{\tilde{R}^{T^{e}}} \quad \text { and } \quad Y^{l}(0, \theta)=\frac{\omega_{2}}{\tilde{R}^{T^{l}}}
$$

Substituting these flows into (4) yields the discounted present value of income for the no college choice.

The household chooses consumption in each period of life, $c_{t}$, to maximize the discounted present value of lifetime utility subject to (4).

$$
V^{n}=\max _{c(t)} \sum_{t} \beta^{t} u(c(t))
$$

subject to:

$$
\sum_{t} \frac{c(t)}{\tilde{R}^{t}} \leq Y(0, \theta)
$$

where $\beta$ is the household's discount rate and $u(\cdot)$ is strictly increasing and strictly concave. Assume $R \beta=1$ so that 
the household has an incentive to completely smooth consumption.

Let $V^{n}$ denote the solution of (10). To be clear, this value is independent of the ability of the agent.

\subsubsection{College}

If the agent goes to school, then the discounted present value of net income for the school phase becomes:

$$
Y^{s}(\bar{e}, \theta)=\frac{\omega_{1}(1-\bar{e})-p}{\tilde{R}^{T^{s}}}
$$

with $p=p(\bar{e})$. Here the agent works $(1-\bar{e})$ units of time when not in school and pays tuition $p$. Again, ability does not enter into income during the education phase. Instead, ability is reflected in the return to education.

The incomes during the two working phases are given by:

$$
Y^{e}(\bar{e}, \theta)=\frac{\omega_{1} H(\bar{e}, \theta)}{\tilde{R}^{T^{e}}} \quad \text { and } \quad Y^{l}(\bar{e}, \theta)=\frac{\omega_{2} H(\bar{e}, \theta)}{\tilde{R}^{T^{l}}}
$$

Substituting these flows into (4) yields the discounted present value of lifetime income if college is chosen.

Let $\tilde{V}^{c}(\theta)$ denote the value, dependent on ability, obtained by maximizing lifetime utility subject to a lifetime budget constraint given by $Y(\bar{e}, \theta)$ from (4). The value of college is also influenced by a taste shock, denoted by $\varepsilon$. The taste shocks can reflect differences in parental attitudes about education and/or peer group pressure. They can also reflect determination and grit at the individual level.

The value of college, inclusive of these taste shocks, is given by

$$
V^{c}(\theta, \varepsilon)=\tilde{V}^{c}(\theta)+\varepsilon
$$

\subsubsection{Optimal Choice}

As there are no capital market imperfections, then the household choice of education is simply a comparison of $V^{n}$ and $V^{c}(\theta, \varepsilon)$. Since lifetime income is an increasing function of ability, there will exist a critical value of ability, denoted $\theta^{*}(\varepsilon)$ such that $V^{n}=V^{c}\left(\theta^{*}, \varepsilon\right)$. For this ability and above, college is the optimal choice of the household.

It is certainly possible for a high (low) ability agent to choose no college (college) because of a low (high) draw of the taste shock. Since, for example, the empirical model in (1) includes only a test score, taste shocks would be a source of measured mismatch.

\subsection{Borrowing Constraints}

As noted above, there is considerable evidence suggestive of capital market frictions impacting the education choice. This motivates the inclusion of borrowing constraints in the analysis.

The borrowing constraint limits the amount of debt an agent can accumulate to finance education expenses during the schooling phase. ${ }^{6}$ Though this constraint does not arise directly from an incentive compatibility condition, the borrowing limit is estimated so that the frequency the constraint binds is a result rather than an assumption.

\footnotetext{
${ }^{6}$ For the other phases of the lifecycle, the household is able to perfectly smooth consumption.
} 
Suppose an agent enters the early work period with $B$ of debt outstanding. The value of income over the early and late working years discounted back to the start of the early work period is given by

$$
Y^{e l}(\bar{e}, \theta, B)=Y^{e}(\bar{e}, \theta)+\frac{Y^{l}(\bar{e}, \theta)}{R^{T^{e}}}-B
$$

with $Y^{e}(\bar{e}, \theta)$ and $Y^{l}(\bar{e}, \theta)$ defined above. Since there are no further borrowing constraints, the household will smooth consumption over the early and late working periods given this level of income.

Given the absence of borrowing constraints after the first phase, the household will smooth consumption over the last two phases of life generating a flow of utility captured by the value $V^{e l}(e, \theta, B)$ given by

$$
V^{e l}(e, \theta, B)=u\left(c^{e l}(e, \theta, B)\right) \tilde{\beta}^{\left(T^{e}+T^{l}\right)}
$$

where $\frac{c^{e l}(e, \theta, B)}{\tilde{R}^{T e l}}=Y^{e l}(e, \theta, B) .^{7}$

During the school years, suppose the household is unconstrained and has no outside wealth. The household will borrow $b$ each period and consumes $c^{s}=\omega(1-\bar{e})-p \bar{e}+b$. At the end of the school period, their debt outstanding is $B=b\left(1+R+R^{2}+\ldots R^{T^{s}-1}\right)$.

Let $\bar{B}$ be a ceiling on debt outstanding at the end of the school period. When the constraint binds, i.e. $B>\bar{B}$, the household will continue to smooth consumption during the school phase but it is not able to smooth consumption between the school and working phases. Thus household consumption during each period of the school phase is given by

$$
\frac{c^{s}(\bar{e}, \theta, \bar{B})}{\tilde{R}^{T^{s}}}=\frac{\omega_{1}(1-\bar{e})}{\tilde{R}^{T^{s}}}-p \bar{e}+\bar{B} .
$$

Using (16) as well as the consumption level given by (17), a household that chooses to go to college with a binding borrowing constraint has lifetime utility of $V^{c}(\theta, \bar{B})=\tilde{\beta}^{T^{s}} u\left(c^{s}(\bar{e}, \theta, \bar{B})\right)+\beta^{T^{s}} V^{e l}(e, \theta, B)$. The household will choose to go to college iff $V^{c}(\theta, \bar{B})+\varepsilon \geq V^{n}$. Clearly if the borrowing constraint binds the value of obtaining a college degree is lower.

The analysis ignores outside wealth of the agent. Yet for many students transfers from family members relax borrowing constraints. This can be included in the analysis as an additional source of wealth, denoted $Z$, in (17). ${ }^{8}$ This transfer from parents could be individual specific, depending on a number of factors such as: (i) parental wealth, (ii) ability of their child and (iii) tastes for higher education. ${ }^{9}$ Clearly a large enough $Z$ offsets the effects of a binding borrowing constraint. This will be discussed further in the context of the estimation of a model that includes parental income and/or wealth.

The borrowing constraint can lead to an under-match. Some high ability individuals will choose not to attend college simply because the borrowing constraint limits their ability to smooth consumption and thus reduces the value of education. This will be more costly for small $\bar{B}$ and this will be part of the estimation.

\footnotetext{
${ }^{7}$ Here, $\tilde{R}^{T^{e l}}$ and $\tilde{\beta}^{T^{e}+T^{l}}$ are defined following the notation previously developed.

${ }^{8}$ The constraint becomes

$$
\frac{c^{s}(\bar{e}, \theta, \bar{B})}{\tilde{R}^{T^{s}}}=\frac{\omega_{1}(1-\bar{e})}{\tilde{R}^{T^{s}}}-p \bar{e}+\bar{B}+Z .
$$
}

${ }^{9}$ These interactions are introduced in the model in Section 8. 


\section{Estimation}

This section outlines the estimation approach and the functional forms. It provides a bridge from the theory model to the results presented in the next section.

\subsection{Functional Forms and Calibration}

As in Cooper and Liu (2016), there are some functional form assumptions used in the empirical analysis. The ability distribution is assumed to be Pareto with a parameter of $\phi .{ }^{10}$ Taste shocks are assumed to be uniformly distributed around zero, i.e. $\varepsilon \in[-\bar{\varepsilon}, \bar{\varepsilon}]$. The parameters $(\phi, \bar{\varepsilon})$ are estimated. Period utility is represented by $u(c)=\ln (c)$. The discount factor is $\beta=\frac{1}{R}$ with $R=1.025 .{ }^{11}$ Section 5.3 relaxes some of these assumptions and studies robustness of our findings.

The analysis uses the ASVAB test score in the estimation of (1) from data. In the model, a test score is simulated from the agents' ability according to:

$$
t s_{i}=\theta_{i}+\sigma \zeta_{i}
$$

Here $\zeta_{i}$ is noise in the mapping between ability and the test score of agent $i^{12}$ The parameter $\sigma$ controls the amount of noise and is estimated. The rank of an agent's test score, based upon $t s_{i}$, is used in the structural estimation, parallel to the data analysis.

This noise becomes another source of mismatch. But unlike a binding borrowing constraint or a taste shock, this mismatch reflects an underlying measurement problem. In the Cooper and Liu (2016) cross-country study, this was the major source of (measured) mismatch.

The human capital accumulation equation is given by $H(\bar{e}, \theta)=h(\bar{e}) \theta$ and $H(0, \theta)=1$ for all $\theta$. The return to education, $h(\bar{e})$, is estimated by gender, race and SES. Note that this specification assumes a complementarity between ability and education as the difference $H(\bar{e}, \theta)-H(0, \theta)$ is increasing in $\theta$. This is common in the literature though there are some notable exceptions, such as Fang (2006).

There are a number of variables calibrated for the analysis. From Table B1 in Johnson (2013), the cost of going to school, relative to labor income in the school phase, is $\frac{p}{\omega_{1}}=0.25$. From the labor market outcomes reported in Table 2 of Johnson (2013), the time spent in school is given by $\bar{e}=0.5$. The total cost of going to college is $0.75 * \omega_{1}$. The robustness section considers other values for these costs. Both tuition and the opportunity cost of education are assumed constant across groups.

The wage rate in the initial period is normalized: $\omega_{1}=1$. The wage rate for the late work period, $\omega_{2}$, is set at 1.148. This is taken from estimates of the wage profile for the US in Hanushek, Schwerdt, Wiederhold, and Woessmann (2015). ${ }^{13}$

\footnotetext{
${ }^{10}$ Specifically, the CDF of ability, $\theta$, is given by $1-\theta^{-\phi}$ with a mean of $\frac{\phi}{\phi-1}$.

${ }^{11}$ The curvature of utility and discount factor surely matters for the education choice. But absent data on intertemporal consumption patterns, estimation of these parameters seemed beyond the scope of the analysis. See Cooper and Zhu (2015) for estimation of these parameters given educational attainment.

${ }^{12}$ The noise is drawn from a standard normal distribution.

${ }^{13}$ As a cross-check, lifecycle income profiles were estimated by education group for the PSID and the return for the two age groups was calculated from those estimates. Thanks to Guozhong Zhu for this evidence.
} 
For the estimation, these wage levels do not vary by gender, race and SES. Instead, the parameters, particularly $h(\bar{e})$, are estimated by gender, race and SES to match the moments for each group. Thus underlying differences in return to education which might appear as wage differences are absorbed by the group specific estimates of $h(\bar{e})$. As developed below, the selection into education induces differences across groups in the college wage premium despite the restriction that $\left(\omega_{1}, \omega_{2}\right)$ are not group specific.

\subsection{Approach}

The estimation is through simulated method of moments. The parameter vector $\Theta=(\phi, \bar{\varepsilon}, \sigma, h(\bar{e}), \bar{b})$ is chosen to minimize the distance between simulated and data moments. Formally, the estimation solves

$$
\min _{\Theta} \frac{\left(M^{d}-M^{s}(\Theta)\right)}{M^{d}} W \frac{\left(M^{d}-M^{s}(\Theta)\right)^{\prime}}{M^{d}}
$$

where $W$ is the identity matrix. Here $M^{d}$ are data moments and $M^{s}(\Theta)$ are moments calculated from simulated data. The procedure solves the household choice problem given the parameter vector $\Theta$. Given these choices, a large data set (100,000 individuals) is simulated. The moments in $M^{s}(\Theta)$ are calculated, with one exception, from the simulated data in exactly the same manner as the data moments. ${ }^{14}$

The distance metric is the percentage difference between simulated and data moments. There is no weighting matrix used in the analysis. ${ }^{15}$ Adda and Cooper (2003), and references therein, discusses this estimation approach.

The moments used for the estimation are given in Table 1. These are: the college attainment rate, the logistic regression coefficients characterizing individual educational attainment, the under- and over-match rates and the coefficients from the regressions of (log) wages on test scores. These moments and thus the parameter estimates are studied for the entire sample as well as by gender, race and SES.

\section{$5 \quad$ Results}

This section reports initial findings in which there are three potential sources of mismatch: (i) borrowing constraints, (ii) taste (grit) shocks and (iii) mismeasurement due to noisy test scores. The inference is based upon the initial model in which family characteristics and income are absent.

\subsection{Estimates and Moments: Baseline Model}

This section establishes the baseline results. The parameter estimates are reported in Table 2 and the moments in Table 3. The rows correspond to a particular group in the sample. There are two blocks in each table, indicating if there is no borrowing constraint imposed ("No BC") or if a borrowing constraint is estimated, ("BC Baseline"). The "fit" measure is the sum of the percentage differences between the simulated and data moments, as in (19).

\footnotetext{
${ }^{14}$ The exception has to do with the treatment of the test score. In the NLSY97 data, the normalized rank of the test score is reported, where the normalized score is over the entire sample. For computational ease, the ranking is within group in the simulated data. Using simulated data from the baseline model, the overall rank was calculated and the correlation of the within rank and overall rank was 0.98 . The estimation matches a moment based upon this rank.

${ }^{15}$ Section 5.3 presents the estimation using an alternative objective function.
} 
Table 2: Parameter Estimates

\begin{tabular}{c|ccccc} 
group & $\phi$ & $\bar{\varepsilon}$ & $\sigma$ & $h(\bar{e})$ & $\bar{b}$ \\
\hline \hline & \multicolumn{5}{c}{ No BC } \\
all & 1.605 & 25.818 & 0.001 & 0.379 & na \\
male & 1.853 & 23.602 & 0.001 & 0.415 & na \\
female & 1.814 & 16.618 & 0.000 & 0.599 & na \\
white & 2.974 & 15.994 & 0.015 & 0.622 & na \\
black & 1.277 & 29.907 & 0.000 & 0.339 & na \\
low SES & 1.724 & 26.139 & 0.003 & 0.375 & na \\
high SES & 1.997 & 23.136 & 0.002 & 0.504 & na \\
\hline & \multicolumn{5}{c}{ BC Baseline } \\
all & 1.581 & 24.979 & 0.000 & 0.449 & 0.161 \\
male & 1.582 & 26.171 & 0.001 & 0.423 & 0.048 \\
female & 1.555 & 22.639 & 0 & 0.520 & 0.241 \\
white & 2.930 & 14.512 & 0.002 & 0.843 & 0.006 \\
black & 1.303 & 28.258 & 0.019 & 0.411 & 0.133 \\
low SES & 1.617 & 25.553 & 0.004 & 0.452 & 0.000 \\
high SES & 1.785 & 24.982 & 0.004 & 0.546 & 0.011 \\
\hline
\end{tabular}

This table reports parameter estimates for the baseline model without and with borrowing constraints.

This section discusses main findings common to all groups. Section 5.2 is devoted to evaluating differences across groups.

\subsubsection{Borrowing Constraint}

The first finding is evident from the fit measure reported in Table 3. Specifically, comparing the last columns of Table 3 for the cases of borrowing constraints and no borrowing constraints reveals an important result: the model is able to better match the moments with an occasionally binding borrowing constraint.

To be clear, this case estimates $\bar{b}$, the per period borrowing limit during the school phase as a fraction of $\omega_{1}$. Thus the estimation nests the case in which there are no binding borrowing constraints.

The case with borrowing constraints improves the fit of the model for all agents and for each group. The fit improves from 1.192 in the pooled sample to 0.889. As noted earlier, a binding borrowing constraint creates asymmetric mismatch by increasing under-match relative to over-match. This is clear in the results.

Note though that the over-match rate exceeds the under-match rate, even in the baseline model. Thus it seems that the inclusion of borrowing constraints is not enough to produce the observed asymmetry in mismatch rates. However, as discussed in sub-section 6.2, the asymmetries are very apparent in a slightly different measure of mismatch.

To be clear, the presence of a borrowing constraint does not mean it binds for all households. For this discussion, a binding borrowing constraint means that the household education choice switched to no education because of the borrowing constraint.

By this definition, the constraint is likely to bind for households with ability high enough to rationalize college with perfect capital markets but for whom the borrowing constraint makes education too costly. Also, it can bind for relatively low ability households who draw a high taste shock. These households may choose college and use earnings over the middle and late period to support consumption during the education phase. But the borrowing 
Table 3: Moments

\begin{tabular}{c|ccccccc|c} 
& college & under-match & over-match & $\alpha_{0}$ & $\alpha_{1}$ & $\nu_{1}$ & $\nu_{2}$ & fit \\
\hline \hline all & 0.409 & 0.035 & 0.014 & -2.906 & 0.043 & 0.009 & 0.006 & na \\
male & 0.349 & 0.019 & 0.012 & -3.335 & 0.045 & 0.008 & 0.005 & na \\
female & 0.480 & 0.040 & 0.015 & -2.545 & 0.041 & 0.011 & 0.007 & na \\
white & 0.441 & 0.030 & 0.027 & -3.276 & 0.047 & 0.007 & 0.003 & na \\
black & 0.308 & 0.035 & 0.023 & -2.666 & 0.044 & 0.014 & 0.010 & na \\
low SES & 0.300 & 0.029 & 0.015 & -3.157 & 0.041 & 0.009 & 0.006 & na \\
high SES & 0.502 & 0.044 & 0.038 & -2.502 & 0.041 & 0.008 & 0.006 & na \\
\hline & & & No BC & & & & & \\
all & 0.266 & 0.005 & 0.017 & -4.050 & 0.051 & 0.006 & 0.006 & 1.192 \\
male & 0.247 & 0.006 & 0.014 & -4.228 & 0.052 & 0.005 & 0.005 & 0.763 \\
female & 0.371 & 0.000 & 0.018 & -3.625 & 0.056 & 0.010 & 0.009 & 1.451 \\
white & 0.265 & 0.011 & 0.032 & -3.530 & 0.043 & 0.004 & 0.004 & 0.812 \\
black & 0.312 & 0.003 & 0.027 & -3.538 & 0.048 & 0.010 & 0.010 & 1.054 \\
low SES & 0.247 & 0.008 & 0.019 & -4.051 & 0.049 & 0.005 & 0.005 & 0.920 \\
high SES & 0.315 & 0.011 & 0.048 & -2.915 & 0.038 & 0.006 & 0.007 & 0.819 \\
\hline & \multicolumn{7}{c}{ Baseline BC } & \\
all & 0.253 & 0.009 & 0.016 & -3.989 & 0.049 & 0.008 & 0.006 & 0.889 \\
male & 0.227 & 0.012 & 0.014 & -4.196 & 0.050 & 0.007 & 0.005 & 0.364 \\
female & 0.302 & 0.005 & 0.020 & -3.663 & 0.049 & 0.010 & 0.008 & 1.268 \\
white & 0.248 & 0.015 & 0.031 & -3.565 & 0.042 & 0.006 & 0.003 & 0.515 \\
black & 0.291 & 0.008 & 0.026 & -3.531 & 0.046 & 0.011 & 0.009 & 0.786 \\
low SES & 0.229 & 0.012 & 0.018 & -4.074 & 0.048 & 0.007 & 0.005 & 0.575 \\
high SES & 0.273 & 0.020 & 0.048 & -3.016 & 0.036 & 0.007 & 0.006 & 0.631 \\
\hline
\end{tabular}

This table reports data and simulated moments for the estimated models without and with borrowing constraints.

constraint implies that the gains from education, which are not that large due to their relatively low ability, are not enough to compensate for the unequal consumption.

Table 4 studies the determinants of a binding borrowing constraint. The table contains coefficient estimates for the covariates listed in the columns where the dependent variable was whether the borrowing constraint was binding or not. For all the groups, an increase in the taste for education reduces the likelihood of the constraint binding. Logically, for those with high tastes, the desire for more education overcomes the cost of not being able to smooth consumption.

The coefficients on ability are all negative. As discussed Lochner and Monge-Naranjo (2011), in the presence of a borrowing constraint, the influence of ability on education attainment is influenced by two forces. First, high ability agents have higher future earnings and thus want to obtain more education even if their borrowing is limited. This would imply that the coefficient on ability in Table 4 would be negative. Second, high ability agents want to borrow more and the binding constraint effectively reduces the return to education and thus can generate a positive coefficient on ability. For our estimated model, the first effect dominates.

Table 5 explores the impact of the borrowing constraint on college choice. From this table, for all households, at the estimated parameters, the education rate without the borrowing constraint would be $33.0 \%$ while the college 
Table 4: Incidence of Borrowing Constraints

\begin{tabular}{c|cc} 
& ability & taste \\
\hline \hline all & -3.52 & -0.52 \\
male & 0.03 & 0.01 \\
& -4.26 & -0.63 \\
female & 0.05 & 0.01 \\
& -6.33 & -0.74 \\
white & 0.07 & 0.01 \\
& -15.23 & -1.48 \\
black & 0.19 & 0.02 \\
& -1.99 & -0.39 \\
low SES & 0.02 & 0.01 \\
& -3.53 & -0.52 \\
high SES & 0.04 & 0.01 \\
& -4.63 & -0.61 \\
& 0.05 & 0.01 \\
\hline
\end{tabular}

This table reports coefficient estimates from a logit regression where the dependent variable $=1$ iff the education choice changed due to a binding borrowing constraint. The covariates included the agent's ability and taste shock.

Table 5: Impact of Borrowing Constraints

\begin{tabular}{c|ccc} 
& \multicolumn{3}{|c}{ College Attainment Rates } \\
& Data & no BC & BC \\
\hline \hline all & 0.409 & 0.330 & 0.253 \\
male & 0.349 & 0.350 & 0.229 \\
female & 0.480 & 0.387 & 0.299 \\
white & 0.441 & 0.411 & 0.247 \\
black & 0.308 & 0.364 & 0.293 \\
low SES & 0.300 & 0.317 & 0.242 \\
high SES & 0.502 & 0.363 & 0.287 \\
\hline
\end{tabular}

This table reports the effects of borrowing constraints by comparing the fraction choosing college education with perfect capital markets (no binding BC) and with borrowing constraints $(\mathrm{BC})$ at the estimated parameters for the baseline $\mathrm{BC}$ case. 
rate falls to $25.3 \%$ once the constraint is imposed. ${ }^{16}$

Overall, the borrowing constraints reduce the college attendance rates by almost 8 percentage points. Along the same lines, Carneiro and Heckman (2002) conclude "at most $8 \%$ of American youth are subject to short term liquidity constraints that affect their post-secondary schooling." For black households, the borrowing constraint reduces the college rate from $36.4 \%$ to $29.3 \%$. The effect is largest for whites as the college rate drops 16.4 percentage points.

The borrowing constraint influences educational outcomes in two ways. First it impacts the choice of agents over education. This directly influences educational attainment. Second, it creates mismatch in so far as high ability agents face binding constraints. The fact that the coefficient on ability is negative in Table 4 implies that this selection aspect is not that powerful.

\subsubsection{Role of Taste Shocks}

A second main finding regards the role of taste shocks. From Table 2, the range of these shocks is substantial. In comparison, there is no evidence of noise in the test score.

This claim is further substantiated by the panels of Tables 6 and 7 in which the tastes shocks are eliminated ( $" \bar{\varepsilon}==0^{\prime \prime}$ ) and when there is no noise in the test score ( $\left.\sigma==0 "\right)$. For these exercises, the models are re-estimated after setting one of the parameters to zero.

As is clear from these tables, the fit is substantially worse than the baseline when the taste shocks are eliminated. Of course, the estimated model "substitutes" for the taste shocks by adding noise to the test score, as indicated by the estimates of $\sigma$ in the top panel of Tables 6 . The inclusion of the test score coefficient in the wage regression limits the amount of noise in the test score that can be added. The fit is not as good in part from the model's inability to match the mismatch, particularly the under-match, in the data.

But, from Table 7 eliminating the noise in the test score does essentially nothing to the fit of the model. The estimated $\sigma$ is indeed very close to zero.

From the estimation, the mismatch comes from taste shocks. Noise in the test scores is almost irrelevant. Though the taste shock is, by construction, distributed symmetrically around zero, it generates more under-match compared to over-match. The non-linearity is, in part, arising from the logistic function. As noted earlier, mismatch is largest for black households and one source is the larger dispersion of tastes.

\subsubsection{Identification of Key Parameters}

The previous discussion highlights the estimates of the taste shocks and test score noise and the implications of the borrowing constraints. Here we focus on the estimates of ability and the return to education.

To evaluate the estimated parameters and how well the moments are matched, it is useful to characterize the mapping from parameters to moments. Table 8 reports the elasticities of the moments with respect to the parameters. These are computed at the baseline estimates for the pooled sample with an occasionally binding borrowing constraint. ${ }^{17}$

\footnotetext{
${ }^{16}$ To be clear, this exercise computes the fraction attaining college with and without the borrowing constraint at the estimated parameters for the baseline borrowing constraint model.

${ }^{17}$ At the baseline, each of the parameters is varied, the model is resolved and the moments are recomputed. In doing so, the 20 th and 80th percentiles of the distribution of predicted educational attainment changes since the logistic regression coefficients from (1) adjust. Thus the under-match and over-match rates adjust both because decisions change and because the cut-offs change.
} 
Table 6: Additional Parameter Estimates

\begin{tabular}{|c|c|c|c|c|c|}
\hline & $\phi$ & $\bar{\varepsilon}$ & $\sigma$ & $h(\bar{e})$ & $\bar{b}$ \\
\hline & \multicolumn{5}{|c|}{ Estimated No Taste Shocks: $\bar{\varepsilon}==0$} \\
\hline all & 1.165 & 0 & 2.731 & 0.388 & 0.971 \\
\hline male & 1.982 & 0 & 0.776 & 0.786 & 0.667 \\
\hline female & 1.826 & 0 & 0.686 & 0.758 & 0.985 \\
\hline white & 2.865 & 0 & 0.666 & 0.960 & 0.720 \\
\hline black & 1.230 & 0 & 1.815 & 0.547 & 1.222 \\
\hline low SES & 1.709 & 0 & 1.283 & 0.663 & 0.612 \\
\hline \multirow[t]{2}{*}{ high SES } & 2.153 & 0 & 1.030 & 0.812 & 1.329 \\
\hline & \multicolumn{5}{|c|}{ Estimated No Test Noise: $\sigma==0$} \\
\hline all & 1.570 & 25.198 & 0 & 0.443 & 0.175 \\
\hline male & 1.674 & 23.977 & 0 & 0.484 & 0.001 \\
\hline female & 1.555 & 22.639 & 0 & 0.520 & 0.241 \\
\hline white & 2.927 & 14.504 & 0 & 0.842 & 0.005 \\
\hline black & 1.353 & 26.050 & 0 & 0.477 & 0.016 \\
\hline low SES & 1.631 & 25.407 & 0 & 0.454 & 0.009 \\
\hline high SES & 1.805 & 24.641 & 0 & 0.557 & 0.002 \\
\hline
\end{tabular}

This table reports parameter estimates for the no taste shocks and the no test noise cases.

The first row shows how the simulated moments respond to variations in the parameter of the ability distribution, $\phi$. An increase in $\phi$ reduces the mean of the ability distribution and thus reduces the college rate. At this lower college attainment rate there is more under-match and more over-match. Changes in the distribution of ability also reduce the response of the education decision and wages to the test score. When $\phi$ increases, evidently the test score becomes less informative about ability.

The return to education, $h(\bar{e})$, not surprisingly, impacts the college attainment rate. As the college rate increases, both the under-match and the over-match rates rise. The regression coefficients are also sensitive to the return to education: (i) the test score is less important in the logistic regression and (ii) wages become more responsive to the test score.

The channels through which these parameters operate are complex. This is particularly the case for the undermatch and over-match moments since changes in parameters impact the entire distribution of predicted probabilities of college, not just the position of a single agent. What should be clear from the table is that, with the exception of the noise in the test score, locally the variation in parameters has a relatively large influence on the moments.

\subsection{Across Groups}

This discussion focuses on differences across groups, both in terms of moments and parameters. It presents a counterfactual exercise where groups are forced to have some common parameters.

\subsubsection{Moments and Parameters}

One striking feature of the data is the relative variations in moments across groups. The college rate as well as the mismatch rates vary widely: the college rate for the high SES groups is about 20 percentage points above the low SES group. The under-match rates for females are about twice that of males and the over-match rates are more 
Table 7: Additional Moments

\begin{tabular}{|c|c|c|c|c|c|c|c|c|}
\hline & college & under-match & over-match & $\alpha_{0}$ & $\alpha_{1}$ & $\nu_{1}$ & $\nu_{2}$ & fit \\
\hline \multicolumn{9}{|c|}{ Baseline BC } \\
\hline all & 0.253 & 0.009 & 0.016 & -3.989 & 0.049 & 0.008 & 0.006 & 0.889 \\
\hline male & 0.227 & 0.012 & 0.014 & -4.196 & 0.050 & 0.007 & 0.005 & 0.364 \\
\hline female & 0.302 & 0.005 & 0.020 & -3.663 & 0.049 & 0.010 & 0.008 & 1.268 \\
\hline white & 0.248 & 0.015 & 0.031 & -3.565 & 0.042 & 0.006 & 0.003 & 0.515 \\
\hline black & 0.291 & 0.008 & 0.026 & -3.531 & 0.046 & 0.011 & 0.009 & 0.786 \\
\hline low SES & 0.229 & 0.012 & 0.018 & -4.074 & 0.048 & 0.007 & 0.005 & 0.575 \\
\hline high SES & 0.273 & 0.020 & 0.048 & -3.016 & 0.036 & 0.007 & 0.006 & 0.631 \\
\hline \multicolumn{9}{|c|}{ Estimated No Taste Shocks: $\bar{\varepsilon}==0$} \\
\hline all & 0.265 & 0.000 & 0.020 & -4.505 & 0.058 & 0.012 & 0.005 & 1.965 \\
\hline male & 0.320 & 0.000 & 0.016 & -4.358 & 0.062 & 0.011 & 0.004 & 1.523 \\
\hline female & 0.426 & 0.000 & 0.020 & -3.463 & 0.059 & 0.012 & 0.007 & 1.450 \\
\hline white & 0.342 & 0.006 & 0.035 & -2.979 & 0.042 & 0.007 & 0.003 & 0.856 \\
\hline black & 0.376 & 0.000 & 0.028 & -3.374 & 0.052 & 0.015 & 0.008 & 1.254 \\
\hline low SES & 0.277 & 0.000 & 0.020 & -4.311 & 0.057 & 0.010 & 0.004 & 1.520 \\
\hline high SES & 0.423 & 0.009 & 0.049 & -2.189 & 0.036 & 0.009 & 0.004 & 0.855 \\
\hline \multicolumn{9}{|c|}{ Estimated No Test Noise: $\sigma==0$} \\
\hline all & 0.253 & 0.009 & 0.015 & -4.016 & 0.050 & 0.008 & 0.006 & 0.889 \\
\hline male & 0.229 & 0.011 & 0.014 & -4.206 & 0.050 & 0.007 & 0.005 & 0.395 \\
\hline female & 0.302 & 0.005 & 0.020 & -3.663 & 0.049 & 0.010 & 0.008 & 1.268 \\
\hline white & 0.247 & 0.015 & 0.030 & -3.588 & 0.042 & 0.006 & 0.003 & 0.516 \\
\hline black & 0.296 & 0.007 & 0.029 & -3.455 & 0.045 & 0.011 & 0.009 & 0.833 \\
\hline low SES & 0.229 & 0.012 & 0.018 & -4.072 & 0.048 & 0.007 & 0.005 & 0.581 \\
\hline high SES & 0.273 & 0.020 & 0.048 & -3.018 & 0.036 & 0.007 & 0.006 & 0.632 \\
\hline
\end{tabular}

This table reports simulated moments for the baseline and some counterfactuals.

than three times larger for the high SES group compared to males. Yet, the variation in the response of wages to test scores is much smaller across these groups.

While the estimated model does generate some dispersion in college rates by gender and race, the differences are not nearly as large as in the data. These differences in college rates reflect group specific estimates of the ability distribution and the returns to education. But often these pull in different directions since these same parameters influence the returns to education, $\left(\nu_{1}, \nu_{2}\right)$. For example, the high college rate for females follows from a relatively high estimate of $h(\bar{e})$ and relatively low estimate of $\phi$. Likewise, whites have the highest estimated values of $\phi$ and $h(\bar{e})$, one of the lowest predicted college rates and a low estimated return to education captured by $\left(\nu_{1}, \nu_{2}\right)$. In this case, the effect of the high $\phi$ dominates. For blacks, the estimated return to education, $h(\bar{e})$, is lower than for other groups, offsetting the low estimate of $\phi$ and thus contributing to the lower college rate and high estimated return to education.

\subsubsection{Counterfactuals}

This exercise studies, through counterfactuals, which of the differences in parameters across the groups is more important for the observed patterns in moments. To do so, one of the parameters for each group is replaced by the estimates from the "all" case. The remaining parameters are kept at their estimated values from the baseline model with borrowing constraints, as indicated in Table 2. This exercise gauges the importance of each of the "behavioral" 
Table 8: Elasticities of Moments

\begin{tabular}{c|ccccccc} 
parameter & college & under-match & over-match & $\alpha_{0}$ & $\alpha_{1}$ & $\nu_{1}$ & $\nu_{2}$ \\
\hline \hline$\phi$ & -0.566 & 0.909 & 1.951 & 0.063 & -0.500 & -2.110 & -2.210 \\
$\bar{\varepsilon}$ & 0.529 & 1.523 & 11.545 & -3.213 & -2.660 & 0.173 & 1.567 \\
$\sigma$ & 0.000 & 0.001 & 1.002 & -0.094 & -0.096 & 0.003 & 0.008 \\
$h(\bar{e})$ & 0.862 & 0.426 & 8.067 & -2.390 & -1.544 & 1.322 & 1.958 \\
$\bar{b}$ & 0.073 & 0.023 & 2.411 & -0.251 & -0.189 & 0.087 & 0.250 \\
\hline
\end{tabular}

This table reports elasticities of moments with respect to parameters for the baseline model with borrowing constraints for the pooled sample.

parameters individually to understand which are responsible for the observed differences in mismatch.

The results are displayed in Table 22, in the appendix. For all groups, the differences in $\phi$ are important. As indicated in the 'Same Ability' block, when all groups are forced to have the same ability parameter the fit deteriorates, particularly for whites. But these changes in moments and thus fit are not large compared to other parameter variations.

Imposing the same tastes has a very large impact on both whites and blacks. Making the taste distribution the same, reduces the range for blacks and increases it for whites. The black college rate falls and it rises for the whites relative to the baseline. This change in parameterization leads to a substantial increase in mismatch for the white and almost eliminates mismatch for blacks.

Imposing the same return from college leads to relatively large changes in the fit except for the low SES group. The college rate rises considerably for blacks, as does the over-match rate, when the return to education is higher. In contrast, the white college rate falls with a lower return and there is almost no mismatch.

Finally, imposing the same borrowing limit has a considerable impact on females and blacks. The college rate rises for females and falls slightly for blacks, for whom the over-match rate nearly doubles.

From the perspective of mismatch, the key to understanding the differences across groups stems largely from differences in tastes and the returns to education. Relative to the baseline estimates, reducing the dispersion in tastes, as in the case of blacks, leads to a reduction in mismatch. Increasing the dispersion of tastes, as in whites, implies large increases in mismatch. The differences in returns to education are also very important for mismatch, as indicated for both blacks and whites.

\subsection{Robustness}

This subsection studies the robustness of these findings. It considers variations in the calibrated parameters and the use of a weighting matrix. Results are shown for the baseline model with borrowing constraints.

\subsubsection{Calibrated Parameters}

The baseline model assumed log utility and imposed a college cost of $25 \%$ of the compensation received by young workers. Instead, consider a CRRA representation of utility, $u(c)=\frac{c^{1-\gamma}}{1-\gamma}$, with the parameter $\gamma=2$, as in Johnson (2013). Further, consider a higher cost of education, increasing the price by $20 \%$. For both of these exercises, the model is re-estimated. The results are reported in Tables 23 and 24, found in the Appendix. There are two key 
findings.

First, as with the baseline parameters, noise in the test score plays essentially no role. That is, the estimated value of $\sigma$ is near zero for all the cases. Instead, mismatch comes from either the taste shock or, in some cases, occasionally binding borrowing constraints. Second, the models with borrowing constraints fit better than those with perfect capital markets. ${ }^{18}$

\subsubsection{Weighting Matrix}

The last experiment replaces (19) with a weighting matrix equal to the inverse of a matrix with the variances of the moments along the diagonal. This objective is given in (20).

$$
\min _{\Theta}\left(M^{d}-M^{s}(\Theta)\right) W\left(M^{d}-M^{s}(\Theta)\right)^{\prime}
$$

This weighting matrix puts considerably more weight on matching the coefficients from the wage regression. As indicated in the tables in the Appendix, the same patterns in estimates and moments remain. The noise in the test score remains small. Second, there is again an improvement in fit once the borrowing constraint is introduced.

\section{Implications}

This section uses the baseline model to discuss two implications. The first is a decomposition of the college wage premium. The second is an expanded discussion of mismatch using a measure that is common across groups.

\subsection{Decomposing the College Premium}

This section studies the implications of the model for the college wage premium. The difference in returns to college matters for the education choice and hence for mismatch. Here, the analysis decomposes the premium, by race and gender, to understand its determinants.

To study the premium in detail return to the wage regression, given in (3):

$$
E\left[\omega_{i} \mid \cdot\right]=\nu_{02}+\nu_{2} * \text { test }_{i}+\nu_{3} * e d_{i}
$$

In this regression, $e d_{i}$, was a dummy variable for person $i$ denoting college completion or not. Hence this coefficient, from the regressions conditional on race and gender, provides one estimate of the college premium. ${ }^{19}$ In contrast to the baseline model, this coefficient on education, denoted $\nu_{3}$, is included in the set of moments matched in the estimation.

The estimates from the extended model along with the baseline estimates are given in Table 9 . The moments are reported in Table 10. In this second table, the counterfactuals of "Same Ability" and "Same Return" are simulations using the estimates from the "all" case to substitute for the gender/race specific estimates.

\footnotetext{
${ }^{18}$ To reduce the proliferation of tables, the estimates without borrowing constraints are not shown. In fact, the fit of the model with $\gamma=2$ is better than the baseline for some groups. As noted earlier, independently estimating with curvature of the utility function without consumption data seems problematic.

${ }^{19}$ Of course this estimate is from a reduced form relationship with all the usual concerns of omitted variable bias.
} 
Table 9: Parameter Estimates: Return to Education Included

\begin{tabular}{c|ccccc} 
& $\phi$ & $\bar{\varepsilon}$ & $\sigma$ & $h(\bar{e})$ & $\bar{b}$ \\
\hline \hline & \multicolumn{5}{|c}{ Baseline: $\nu_{3}$ estimated } \\
all & 1.481 & 24.994 & 0.000 & 0.448 & 0.166 \\
male & 1.721 & 23.321 & 0.002 & 0.502 & 0.000 \\
female & 1.645 & 19.776 & 0.007 & 0.589 & 0.218 \\
white & 2.955 & 14.398 & 0.003 & 0.845 & 0.009 \\
black & 1.357 & 25.000 & 0.000 & 0.507 & 0.000 \\
low SES & 1.536 & 24.960 & 0.008 & 0.466 & 0.000 \\
high SES & 1.751 & 24.910 & 0.005 & 0.552 & 0.000 \\
& \multicolumn{5}{c}{ Same Ability } \\
all & 1.481 & 24.994 & 0.000 & 0.448 & 0.166 \\
male & 1.481 & 24.583 & 0.007 & 0.469 & 0.006 \\
female & 1.481 & 20.714 & 0.004 & 0.563 & 0.240 \\
white & 1.481 & 24.685 & 0.490 & 0.419 & 0.002 \\
black & 1.481 & 24.994 & 0.006 & 0.499 & 0.000 \\
low SES & 1.481 & 24.999 & 0.003 & 0.451 & 0.171 \\
high SES & 1.481 & 25.000 & 0.000 & 0.529 & 0.042 \\
& \multicolumn{5}{c}{ Same Return } \\
male & 1.607 & 24.998 & 0.007 & 0.448 & 0.052 \\
female & 1.379 & 22.279 & 0.022 & 0.448 & 0.465 \\
white & 1.783 & 18.129 & 0.644 & 0.448 & 0.726 \\
black & 1.263 & 25.000 & 0.214 & 0.448 & 0.085 \\
low SES & 1.551 & 24.992 & 0.000 & 0.448 & 0.110 \\
high SES & 1.519 & 24.975 & 0.082 & 0.448 & 0.216 \\
\hline
\end{tabular}

This table reports parameter estimates for the model with education as a covariate $\left(\nu_{3}\right)$ in the wage regression included in the moments.

Focus first on the $\nu_{3}$ coefficient in the "Data" block of Table 10 as it is informative about the college premium by group. This coefficient is positive for all groups and largest for the black and female groups. From the NCES data, the 2012 premia follow a similar pattern: the premium is larger for blacks than whites and larger for females compared to males. ${ }^{20}$

Including this moment generates the parameter estimates in Table 9. Qualitatively the parameter estimates are quite similar to the baseline estimates. The $\phi$ is lowest for blacks and that group has high taste variability, and a low return to college. As in the baseline with $\nu_{3}==0$, this group also has the tightest borrowing constraint. Whites, in contrast, have the lowest mean ability, the smallest taste shock and the highest return to school.

The fit of the expanded model is not much worse than the baseline with $\nu_{3}==0$. The $\nu_{3}$ estimates from the simulated data are relatively large (compared to the return to the test score), though not as large as in the data. Overall, the model does capture the joint returns to the test score and education.

Generally, the measured average college premium reflects two forces: (i) the physical return to schooling, $h(\bar{e})$ and (ii) the selection of college attainment by ability. In principal, the relative magnitude of these factor may differ across gender and race. From the model, in the late working period the college wage premium is given by $E \frac{\omega_{2} h(e) \theta}{\omega_{2}}=h(\bar{e}) E(\theta \mid e=\bar{e})$.

Using this expression, Table 11 shows decompositions of the college premium by gender and race. These are

\footnotetext{
${ }^{20}$ These are taken from median earnings reported at https://nces.ed.gov/programs/digest/d16/tables/dt16_502.30.asp.
} 
Table 10: Moments: Return to Education Included

\begin{tabular}{|c|c|c|c|c|c|c|c|c|c|}
\hline & college & under-match & over-match & $\alpha_{0}$ & $\alpha_{1}$ & $\nu_{1}$ & $\nu_{2}$ & $\nu_{3}$ & fit \\
\hline \multicolumn{10}{|c|}{ Data } \\
\hline all & 0.409 & 0.035 & 0.014 & -2.906 & 0.043 & 0.009 & 0.006 & 0.345 & na \\
\hline male & 0.349 & 0.019 & 0.012 & -3.335 & 0.045 & 0.008 & 0.005 & 0.302 & na \\
\hline female & 0.480 & 0.040 & 0.015 & -2.545 & 0.041 & 0.011 & 0.007 & 0.468 & na \\
\hline white & 0.441 & 0.030 & 0.027 & -3.276 & 0.047 & 0.007 & 0.003 & 0.375 & na \\
\hline black & 0.308 & 0.035 & 0.023 & -2.666 & 0.044 & 0.014 & 0.010 & 0.433 & na \\
\hline low SES & 0.300 & 0.029 & 0.015 & -3.157 & 0.041 & 0.009 & 0.006 & 0.450 & na \\
\hline high SES & 0.502 & 0.044 & 0.038 & -2.502 & 0.041 & 0.008 & 0.006 & 0.239 & na \\
\hline \multicolumn{10}{|c|}{ Baseline: $\nu_{3}$ estimated } \\
\hline all & 0.268 & 0.007 & 0.014 & -3.982 & 0.051 & 0.009 & 0.007 & 0.245 & 1.028 \\
\hline male & 0.229 & 0.011 & 0.014 & -4.210 & 0.050 & 0.007 & 0.005 & 0.285 & 0.405 \\
\hline female & 0.315 & 0.003 & 0.018 & -3.703 & 0.051 & 0.010 & 0.008 & 0.322 & 1.396 \\
\hline white & 0.248 & 0.015 & 0.031 & -3.565 & 0.042 & 0.006 & 0.003 & 0.358 & 0.520 \\
\hline black & 0.304 & 0.006 & 0.028 & -3.463 & 0.046 & 0.012 & 0.009 & 0.362 & 0.878 \\
\hline low SES & 0.244 & 0.009 & 0.017 & -4.052 & 0.049 & 0.008 & 0.006 & 0.293 & 0.754 \\
\hline high SES & 0.277 & 0.019 & 0.048 & -3.008 & 0.036 & 0.008 & 0.006 & 0.221 & 0.643 \\
\hline \multicolumn{10}{|c|}{ Same Ability } \\
\hline male & 0.237 & 0.010 & 0.014 & -4.168 & 0.050 & 0.008 & 0.006 & 0.284 & 0.423 \\
\hline female & 0.314 & 0.003 & 0.018 & -3.709 & 0.051 & 0.010 & 0.008 & 0.310 & 1.404 \\
\hline white & 0.199 & 0.008 & 0.029 & -4.414 & 0.050 & 0.006 & 0.004 & 0.322 & 1.086 \\
\hline black & 0.261 & 0.012 & 0.029 & -3.564 & 0.044 & 0.008 & 0.007 & 0.266 & 1.079 \\
\hline low SES & 0.255 & 0.009 & 0.016 & -3.952 & 0.049 & 0.008 & 0.006 & 0.201 & 0.917 \\
\hline high SES & 0.296 & 0.013 & 0.041 & -3.091 & 0.040 & 0.009 & 0.008 & 0.247 & 0.824 \\
\hline \multicolumn{10}{|c|}{ Same Return } \\
\hline male & 0.232 & 0.011 & 0.012 & -4.220 & 0.050 & 0.007 & 0.005 & 0.234 & 0.445 \\
\hline female & 0.309 & 0.002 & 0.016 & -3.790 & 0.052 & 0.011 & 0.009 & 0.227 & 1.677 \\
\hline white & 0.220 & 0.002 & 0.031 & -4.312 & 0.050 & 0.006 & 0.004 & 0.277 & 1.352 \\
\hline black & 0.296 & 0.003 & 0.025 & -3.869 & 0.052 & 0.012 & 0.009 & 0.371 & 1.128 \\
\hline low SES & 0.250 & 0.009 & 0.014 & -4.073 & 0.050 & 0.008 & 0.006 & 0.233 & 0.893 \\
\hline high SES & 0.273 & 0.008 & 0.041 & -3.579 & 0.045 & 0.009 & 0.007 & 0.187 & 1.164 \\
\hline
\end{tabular}

This table reports data and simulated moments for the estimated model adding the education coefficient in the log wage regression as a moment, denoted $\nu_{3}$. The counterfactuals are simulated, not re-estimated.

calculated from simulated data based upon the estimated model with $\nu_{3}$ included in the moments. This analysis uses, for the two counterfactual exercises, either the same value of $\phi$ or $h(\bar{e})$ imposed as the "Same Ability" or "Same Return" cases respectively.

There are a couple of key points from this table. First the college wage premium is largest for blacks and smallest for whites. Second, the estimated return to education is nearly the opposite: relatively low for blacks and the highest for whites. This difference is reconciled by selection. The mean of ability for college education relative to no college is about 8.1 for blacks and only about 2.1 for whites. The low SES group has a strong selection effect as well compared to the high SES.

The two counterfactuals shown in Table 11 make clear how the college premium and the selection depends on differences in ability and return. The moments from these counterfactuals are shown in Table 10. These models do not fit as well as the baseline, with the imposition of the same returns generating the largest deterioration.

Imposing the same ability eliminates the wage premium for blacks, though the selection effect remains strong. 
Table 11: Decomposing the College Wage Premium

\begin{tabular}{|c|c|c|c|c|}
\hline & college prem. & $h(\bar{e})$ & $E(\theta \mid e=\bar{e})$ & $E(\theta \mid e=0)$ \\
\hline & \multicolumn{4}{|c|}{ Baseline } \\
\hline all & 2.965 & 0.448 & 6.615 & 1.757 \\
\hline male & 2.422 & 0.502 & 4.825 & 1.665 \\
\hline female & 2.761 & 0.589 & 4.686 & 1.569 \\
\hline white & 1.783 & 0.845 & 2.109 & 1.317 \\
\hline black & 4.096 & 0.507 & 8.084 & 1.822 \\
\hline low SES & 2.903 & 0.466 & 6.226 & 1.767 \\
\hline high SES & 2.267 & 0.552 & 4.107 & 1.655 \\
\hline & \multicolumn{4}{|c|}{ Same Ability } \\
\hline male & 2.874 & 0.502 & 5.724 & 1.710 \\
\hline female & 2.971 & 0.589 & 5.043 & 1.582 \\
\hline white & 3.852 & 0.845 & 4.556 & 1.462 \\
\hline black & 2.721 & 0.507 & 5.370 & 1.728 \\
\hline low SES & 2.695 & 0.466 & 5.779 & 1.745 \\
\hline high SES & 2.785 & 0.552 & 5.044 & 1.706 \\
\hline & \multicolumn{4}{|c|}{ Same Return } \\
\hline male & 2.420 & 0.448 & 5.414 & 1.689 \\
\hline female & 2.749 & 0.448 & 6.150 & 1.646 \\
\hline white & 1.780 & 0.448 & 3.983 & 1.416 \\
\hline black & 4.056 & 0.448 & 9.075 & 1.859 \\
\hline low SES & 2.902 & 0.448 & 6.492 & 1.775 \\
\hline high SES & 2.187 & 0.448 & 4.892 & 1.689 \\
\hline
\end{tabular}

The college premium is the ratio of earnings in the late work phase for agents with college and without and $h(\bar{e})$ is the estimated return to college independent of ability. These calculations are from the estimated model with borrowing constraints, adding $\nu_{3}$ as a parameter.

The premium for whites more than doubles and the selection effect is stronger.

Imposing the same return provides another perspective on the decomposition of the wage premium. In this case, the selection effect is stronger for blacks and whites to compensate for the reduced return to college. The premia are close to the baseline estimates.

\subsection{Other Measures of MisMatch}

As explained earlier, the measure of mismatch is group specific. Under-match, for example, represents individuals without a college education whose predicted probability of education exceeds the 80th percentile of the predicted values of individuals with college attainment within the individual's own group. Under- and over-match are defined in the same way in the simulated data to match moments. So this is not an issue for the estimation per se.

But, for interpretation it is also useful to look at the calculation of mismatch relative to the whole population. So, for example, the under-match rate for males would be calculated using the 80th percentile of the predicted values of individuals with college attainment for all groups, i.e. using a common threshold.

The baseline and this alternative measure of mismatch are shown in Table 12. There are some interesting differences across these measures. The starkest are the large increases in the under-match rates for the female and black groups. The under-match rate is about 10 times larger for females and 5 times larger for blacks with this new measure. Further, the asymmetry is apparent for these groups. 
These groups are under-matched relative to the whole population but not relative to their own group. That is, there are females or blacks with relatively high test scores who do not go to college. Relative to those within their own group, these scores and thus the predicted probability of college attendance is not that high. But relative to the whole population, these scores are high and thus these agents are under-matched. Note that for the baseline estimates, blacks and females had the lowest estimate of $\phi$ and thus the highest estimated mean ability.

Table 12: Alternative Measure of Mismatch

\begin{tabular}{c|cc|cc} 
& under-match & over-match & under-match & over-match \\
\hline \hline & \multicolumn{2}{|c}{ Baseline } & \multicolumn{2}{c}{ Common Threshold } \\
male & 0.009 & 0.016 & 0.015 & 0.019 \\
female & 0.005 & 0.020 & 0.053 & 0.008 \\
white & 0.015 & 0.031 & 0.008 & 0.010 \\
black & 0.008 & 0.026 & 0.042 & 0.004 \\
low SES & 0.012 & 0.018 & 0.011 & 0.019 \\
high SES & 0.020 & 0.048 & 0.004 & 0.000 \\
\hline
\end{tabular}

This table reports an alternative measure of mismatch in which the thresholds for under and over match are from the "all" estimation treatment rather than group specific.

\section{Non-Cognitive Ability}

The analysis thus far has ignored non-cognitive ability. This omitted factor may be important for our analysis of mismatch. ${ }^{21}$ An individual with a high cognitive test score who does not attend college would be classified as under-matched. Because education choices depends on non-cognitive ability as well, if this individual had low non-cognitive ability, then the decision not to attain a college degree may not reflect mismatch. ${ }^{22}$

This robustness exercise introduces non-cognitive ability into the baseline model, retaining much of that structure. In particular, the agent chooses education attainment given random draws of cognitive and non-cognitive ability. As in Heckman, Stixrud, and Urzua (2006), these draws are assumed to be independent. These components of ability combine to create an aggregated measure of ability, treated as $\theta$ in the above choice model. For this exercise, $\theta$ is assumed to be a constant returns to scale Cobb-Douglas function of cognitive and non-cognitive ability, with the coefficient estimated.

The perceived compensation from education remains $\theta h(\bar{e})$. Through the construction of $\theta$, compensation depends on both components of ability and thus both contribute to the education decision.

The set of moments is altered to include a measure of non-cognitive ability. ${ }^{23}$ First, the same logistic regression to predict education in the baseline model, (1), was supplemented with non-cognitive ability. Second, modify both (2) and (3) to include non-cognitive ability as a regressor. As noted below, for some of these regressions the measure of non-cognitive ability was not statistically significant. ${ }^{24}$

The construct of non-cognitive ability is the Rosenberg measure, taken from NLSY79. ${ }^{25}$ This is one of the measures discussed in Heckman, Stixrud, and Urzua (2006). It is a measure of self-esteem. The other measure used in Heckman, Stixrud, and Urzua (2006), the Rotter scale, was not significant for predicting wages and so was not used.

\footnotetext{
${ }^{21}$ This extension was suggested by James Heckman.

${ }^{22}$ See Heckman, Stixrud, and Urzua (2006) for evidence linking non-cognitive ability and college attainment.

${ }^{23}$ For this exercise, the low and high SES group is omitted due to data limitations.

${ }^{24}$ For the block of moments labeled "Non-Cog", the stars indicate coefficient that are significantly different from zero at a $5 \%$ significance level.

${ }^{25}$ There is no comparable measure in NLSY97.
} 
Table 13: Parameter Estimates: Non-Cognitive Ability

\begin{tabular}{|c|c|c|c|c|c|c|c|}
\hline & $\phi_{c}$ & $\phi_{n c}$ & $\alpha$ & $\bar{\varepsilon}$ & $\sigma$ & $h(\bar{e})$ & $\bar{b}$ \\
\hline Baseline & \multicolumn{7}{|c|}{ No BC } \\
\hline all & 1.479 & na & na & 28.789 & 0.015 & 0.331 & na \\
\hline male & 1.753 & na & na & 24.073 & 0.004 & 0.405 & na \\
\hline female & 1.982 & na & na & 21.850 & 0.001 & 0.485 & na \\
\hline white & 1.612 & na & na & 14.896 & 0.315 & 0.563 & na \\
\hline black & 1.633 & na & na & $\begin{array}{c}29.998 \\
\text { BC }\end{array}$ & 0.000 & 0.350 & na \\
\hline all & 1.366 & na & na & 27.534 & 0.000 & 0.414 & 0.000 \\
\hline male & 1.337 & na & na & 26.504 & 0.033 & 0.412 & 0.050 \\
\hline female & 1.851 & na & na & 21.531 & 0.009 & 0.566 & 0.093 \\
\hline whiate & 2.691 & na & na & 12.970 & 0.010 & 0.877 & 0.018 \\
\hline black & 1.389 & na & na & 29.768 & 0.142 & 0.392 & 0.001 \\
\hline \multicolumn{8}{|l|}{ Non-Cog Wages } \\
\hline & \multicolumn{7}{|c|}{ No BC } \\
\hline all & 1.528 & 1.083 & 0.879 & 18.596 & 0.103 & 0.483 & na \\
\hline male & 1.699 & 1.024 & 0.997 & 13.564 & 0.003 & 0.669 & na \\
\hline female & 1.432 & 1.305 & 0.817 & 24.509 & 7.871 & 0.370 & na \\
\hline white & 1.656 & 1.310 & 0.879 & 14.762 & 0.928 & 0.580 & na \\
\hline black & 1.367 & 4.472 & 0.823 & $\begin{array}{c}29.977 \\
\text { BC }\end{array}$ & 3.285 & 0.331 & na \\
\hline all & 1.661 & 1.071 & 0.966 & 22.763 & 0.024 & 0.437 & 1.212 \\
\hline male & 1.662 & 1.052 & 0.988 & 13.681 & 0.021 & 0.660 & 1.634 \\
\hline female & 1.427 & 1.464 & 0.850 & 24.988 & 7.610 & 0.371 & 1.139 \\
\hline white & 1.618 & 1.773 & 0.801 & 17.794 & 0.235 & 0.495 & 1.340 \\
\hline black & 1.308 & 4.639 & 0.913 & 29.847 & 2.602 & 0.333 & 0.172 \\
\hline \multicolumn{8}{|l|}{ Non-Cog } \\
\hline & \multicolumn{7}{|c|}{ No $B C$} \\
\hline all & 1.708 & 1.365 & 0.841 & 16.763 & 0.037 & 0.556 & na \\
\hline male & 1.690 & 1.063 & 0.958 & 13.089 & 0.028 & 0.664 & na \\
\hline female & 1.148 & 1.033 & 0.666 & 21.196 & 6.637 & 0.385 & na \\
\hline white & 1.666 & 1.400 & 0.812 & 16.542 & 0.893 & 0.542 & na \\
\hline black & 1.272 & 1.534 & 0.805 & $\begin{array}{c}28.520 \\
\text { BC }\end{array}$ & 0.448 & 0.324 & na \\
\hline all & 1.194 & 1.337 & 0.795 & 20.265 & 0.339 & 0.541 & 0.012 \\
\hline male & 1.476 & 1.138 & 0.929 & 18.001 & 0.155 & 0.628 & 0.015 \\
\hline female & 1.084 & 1.004 & 0.661 & 19.847 & 7.315 & 0.458 & 0.035 \\
\hline white & 1.223 & 1.520 & 0.738 & 18.678 & 1.388 & 0.572 & 0.013 \\
\hline black & 1.092 & 1.439 & 0.838 & 29.885 & 0.401 & 0.330 & 0.016 \\
\hline
\end{tabular}

This table reports parameter estimates for the model with both cognitive and non-cognitive ability. 
Table 13 has the parameter estimates and Table 14 reports moments. As indicated by the blocks of these tables, there are three cases. The first, termed "baseline", uses the baseline moments from the NLSY97 baseline. As this case excludes the non-cognitive measures, this facilitates a comparison of estimates across data sets using comparable moments. The second, "non-cog wages" allows the measure of non-cognitive ability to influence wages but not the education decision. The third case, labeled "non-cog", allows non-cognitive ability to impact both wages and the education decision.

The parameters include the coefficient on cognitive ability, denoted $\alpha$ in the Cobb-Douglas technology that combines the two forms of ability to create $\theta$. Second, the noise, $\sigma$, is in the non-cognitive ability measure for the second and third treatments and remains a measure of noise in the cognitive score for the baseline treatment. ${ }^{26}$

Looking first at the baseline, from Table 14, there are some interesting differences in moments across the two samples. The education rates are much closer together in the NLSY79 sample, except for blacks whose college attainment rate is much lower in the earlier sample. The mismatch rates are lower in the NLSY79 sample. Further, under-match rates are less than the over-match rates except for males.

The model fit improves with the presence of borrowing constraints. So, in contrast to previous studies which found no evidence of borrowing constraint in the NLSY79 sample, these constraints improve the fit. The average return to education, $h(\bar{e})$ remains highest for whites and lowest for blacks. The estimated parameters for the Pareto distribution of ability are much less dispersed, with the highest value for whites. The estimated borrowing limits are all close to zero. The fit is better with these tight constraints. There is essentially no noise in the test score except for the black group.

For the "non-cog wages" case, looking at Table 15, the wages regressions indicate the effects of non-cognitive skills through the regression coefficients $\left(\nu_{1 n c}, \nu_{2 n c}\right)$. These more important for females rather than males and blacks more than whites.

For this case, the model with borrowing constraints improves the fit slightly. From the parameter estimates, the model puts nearly $90 \%$ of the weight, through $\alpha$, on cognitive ability. Thus the influence of non-cognitive ability on wages is not very strong.

For the "non-cog" case, the effects of non-cognitive ability on the education choice and wages are reported in Table 15. The significant coefficients (at the $5 \%$ level) on non-cognitive ability are marked with a “*”. These coefficients are significant and positive for the pooled, female and white groups, not for males and blacks.

For this case, again the borrowing constraints matter and improve the fit. From the parameter estimates, noise in the test score is not important and tastes matter. As before the point estimate of $\alpha$ is above 0.5 for all groups, but is only 0.66 for females and 0.738 for whites, allowing non-cognitive ability to matter in the overall ability measure.

Overall, a couple of key results remain with this extension of the model. First, the model with borrowing constraints does fit the data moments slightly better. Second, the main source of mismatch is taste shocks, not noise in the test score. This is true for the baseline as well as the other cases. However, there is considerable noise in the non-cognitive test score for females and whites.

\section{Role of Parents}

Thus far the analysis reaches an important conclusion. Borrowing constraints and taste differences matter for the education decision and generate mismatch.

But it has ignored the role of parents. Disentangling the influence of parents from borrowing constraints is an important check on our finding of the contribution of capital market imperfections to mismatch.

\footnotetext{
${ }^{26}$ Based on the earlier results of no noise in the cognitive measure, confirmed here as well for the NLSY79 baseline, we focus on noise in the non-cognitive test.
} 


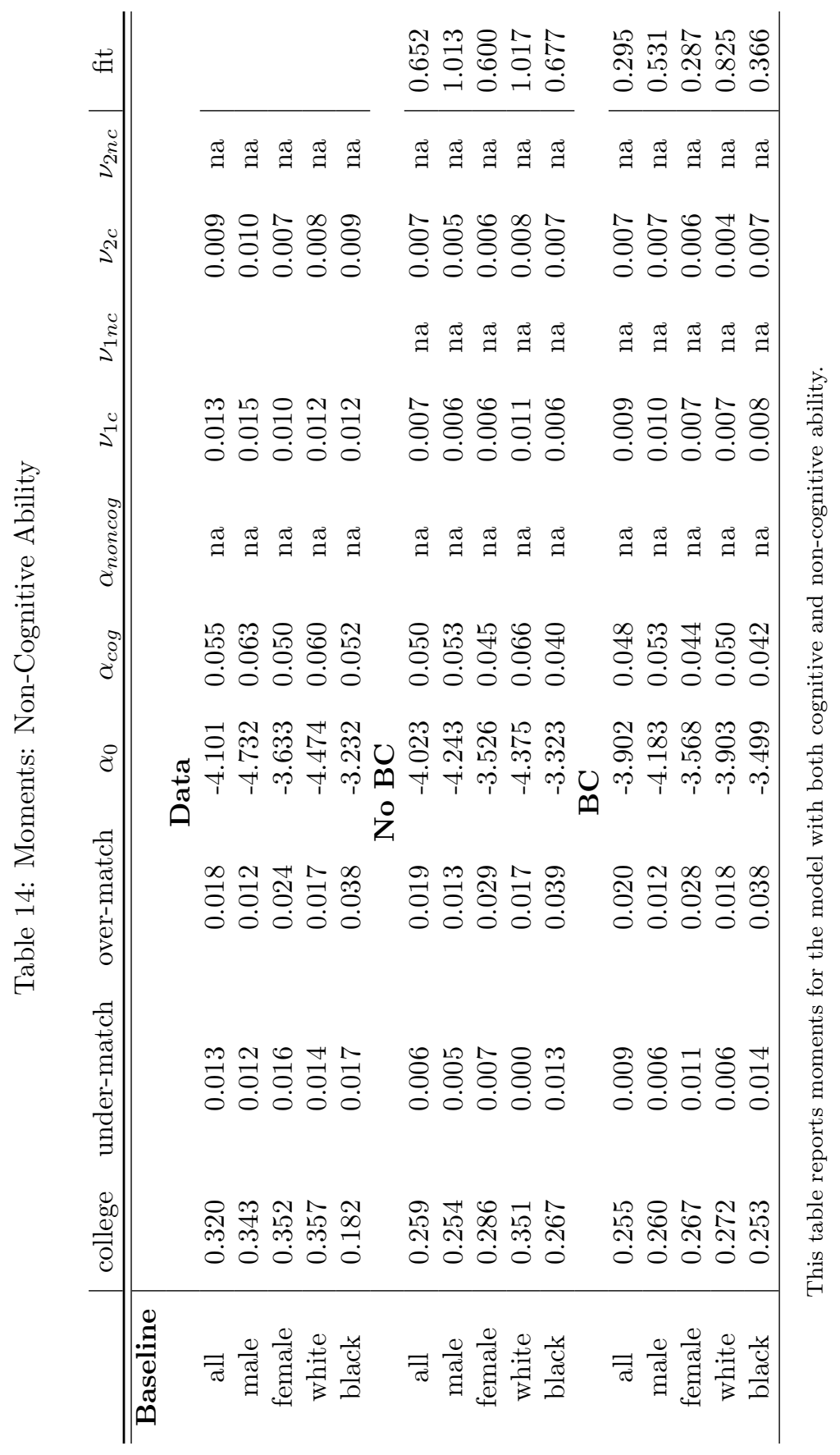




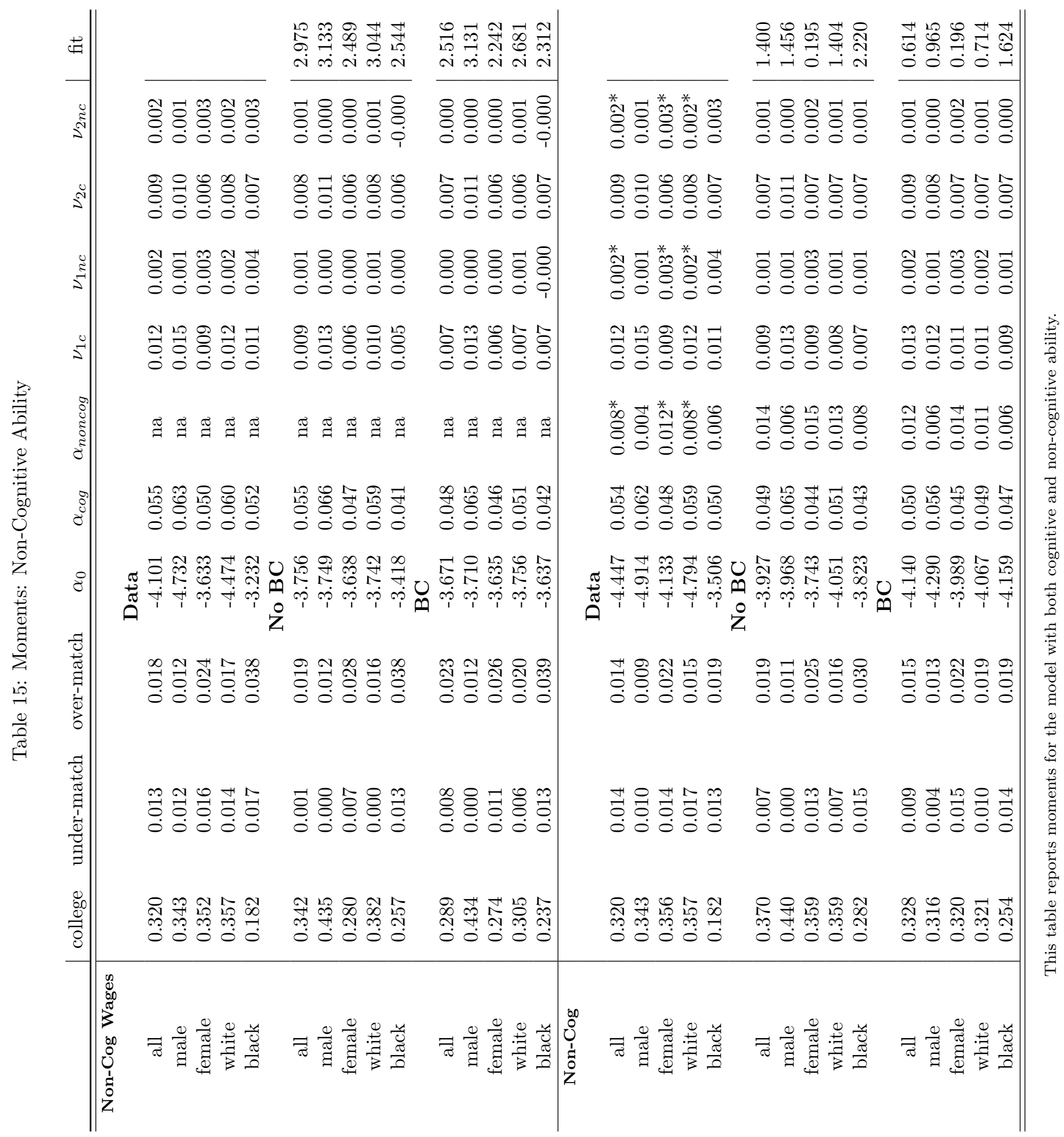


The split between low and high SES groups is indicative. From the baseline moments, the education rate is about 20 percentage points lower and mismatch is also lower for the low SES group. But, the finding in the baseline model that borrowing constraints even improve the fit for the high SES group suggests that perhaps these constraints are not just reflecting capital market imperfections. As we shall see, parents' influence extends well beyond the relaxation of a borrowing constraint.

Accordingly, this section studies the influence of parents on education choice and thus mismatch. It returns to the motivation of distinguishing between the transfer of resources and of direct influence of parents on children through tastes and/or ability: i.e. is it "money or grit?". Here, again, the term "grit" aptly captures non-cognitive influences of parents on the work habits, determination and even role models.

The literature identifies two main channels linking educational attainment with parent's characteristics: (i) the provision of resources and (ii) the creation of environments for the accumulation of human capital (both cognitive and non-cognitive skills). ${ }^{27}$ There is a large extant literature on the relative importance of these links between parents and education attainment. Looking at the NLSY79 sample, Cameron and Heckman (2001), and Carneiro and Heckman (2002) argue that the second channel is the main way in which parents influence the education outcome of their children.

Belley and Lochner (2007a), comparing the NLSY79 and NLSY97 samples, argue that the role of family income has increased over time, partly due to increased tuition between the samples. From their Table 3, both family income and family characteristics, such as the parent's educational attainment, are significant in explaining education for the NLSY97 sample. In fact, the coefficient in the reduced form regression on family income is considerable higher in the NLSY97 sample compared to the NLSY79 sample.

The paper addresses these issues in a couple of ways. First, in sub-section 8.1, the model includes outside family income. The moments to match are supplemented by allowing these flows to influence educational attainment. In one specification, the resource flow is correlated with ability in the model allowing us to match a correlation between the flow and test score in the data. For this extended model the borrowing constraint continues to matter.

Sub-section 8.2 studies the impact of parent's education on either the child's tastes or ability. Here parent's education is correlated with either the taste shock or ability and match, in the latter case, an additional moment linking parent's education to test scores. The estimated model without capital market imperfections matches the moments very well. Adding in the borrowing constraint does not improve the fit of the model. Further, in this case, while there is some noise in the test score, the main factor creating mismatch remains taste shocks.

Sub-section 8.3 allows both channels of influence to operate. Parent's income can relax the borrowing constraint and parent's education can influences tastes. The estimation matches moments including the joint effects of income and parent's education on child educational attainment. Again, there is no evidence of borrowing constraints as a determinant of mismatch.

\footnotetext{
${ }^{27}$ See Cunha, Heckman, and Schennach (2010) and the references therein.
} 


\subsection{Family Income}

This section studies the impact of family resources on the chid's educational attainment and mismatch. Flows from parents were not explicitly incorporated into the educational choice problem specified above. Here we introduce those flows into the model and then re-estimate parameters. This section excludes the low and high SES groups since the analysis is about the impact of family income.

Consider an extension of the model to include a transfer from parents, received at the start of the education phase. ${ }^{28}$ The household head chooses transfers to a child, denoted $Z$, that solves $\max _{Z} u^{p}(Y-Z)+\lambda V(Z, \theta)$ with $u^{p}(\cdot)$, strictly increasing and strictly concave, representing the parents utility given income $Y$ and $V(Z, \theta)$ being the indirect utility of a child with resources $Z$ and ability $\theta$. This value comes from the college choice problem studied in section 3 with $Z$ added to the resources in (17). The parameter $\lambda$ is a weight between the parents consumption and the value of the child's optimization problem. The optimal transfer will be increasing in parent's income. ${ }^{29}$

Though this model is not included explicitly in the estimation, it frames the analysis that follows. The next sub-section considers the effect of family income on college choice. As argued above, the optimal transfer will depend on family income. It is common in the literature on the empirical effects of family income on education choice to treat family income as representing the resources available to the child. The reduced form estimates reported in this section on the dependence of educational attainment on family income provide a useful comparison with these previous findings.

\subsubsection{Additional Moments}

The estimation includes an additional set of moments that link family income to educational attainment. Specifically, a version of the logistic regression, (1), is estimated where both family income and the test score are used as covariates:

$$
\operatorname{Pr}\left(e_{i}=1\right)=\frac{\exp ^{\alpha_{0}^{r}+\alpha_{1}^{r} a_{i}+\mu_{2}^{r} i n c_{i}^{2}+\mu_{3}^{r} i n c_{i}^{3}+\mu_{4}^{r} i n c_{i}^{4}}}{1+\exp ^{\alpha_{0}^{r}+\alpha_{1}^{r} a_{i}+\mu_{2}^{r} i n c_{i}^{2}+\mu_{3}^{r} i n c_{i}^{3}+\mu_{4}^{r} i n c_{i}^{4}}}{ }^{3}
$$

As in Belley and Lochner (2007a), family income is included through dummy variables indicating the quartile of the income distribution. But, in contrast to Belley and Lochner (2007a), the dependent variable is educational attainment not enrollment. ${ }^{31}$ The regression coefficients are denoted $\mu_{j}^{r}$ where $j$ is the index of the quartile (with $j=1$ excluded). The test score is continuous with a coefficient of $\alpha_{1}^{r}$ in the regression with family income as additional covariates.

Note that the additional moments use the quartile of family income as a proxy for family resources and thus transfers. Since the transfer function is monotone in income, the quartile of family income is a good proxy for the quartile of the transfer.

These results from estimation of (22), for the entire sample as well as the sub-groups, are shown in Table 16. In the data, the response of the education choice to family income is not monotone. The coefficients for the second

\footnotetext{
${ }^{28}$ Appendix B of Belley and Lochner (2007b) outlines a more elaborate model along the same lines. Of course, the transfer may take many forms. As in Glomm and Ravikumar (1992), parents may directly choose education quality for their children.

${ }^{29}$ This follows directly from the strict concavity of $u^{p}(\cdot)$ and the curvature of $V(Z, \theta)$ with respect to $Z$. The dependence of the transfer on ability is complicated by both the education decision as well as the potentially binding borrowing constraint.

${ }^{30}$ Weaker results obtain when using a measure of wealth rather than family income. In keeping with the literature, such as Belley and Lochner (2007a), we focus on family income and not wealth.

${ }^{31}$ For their linear regression the dependent variable was educational attainment, in years, at age 21.
} 
group are negative, indicating an adverse affect of family income of educational attainment relative to the lowest income group. This could reflect educational subsidies for the lowest family income group. The coefficients are positive for the third and fourth groups. ${ }^{32}$ The coefficients are statistically significant at the $5 \%$ level for all groups except for the coefficient on the second group which is significant only for the pooled sample and the white group. The coefficient on the test score in regression (22) is generally quite close to that from regression (1).

In terms of other moments, the mismatch rates continue to be calculated based upon the initial regression, conditioning only on the test score, as in (1). Thus the regression coefficients from (22) are in addition to the original set of moments.

The simulated data are created by solving our model with the inclusion of a transfer $Z$. Since family income is used as a proxy for the transfer, the distribution of $Z$ is assumed to be Pareto and a single parameter is calibrated by race and gender to match mean family income from the NLSY97 sample. ${ }^{33}$

\subsubsection{Estimation Results}

There are two cases explored, distinguished by the way family income enters the model. In the first, termed "No Correlation", parents income influences the household choice problem only through the direct provision of resources. This will influence the education choice since utility is strictly concave so that the transfer impacts the marginal utility of consumption during the schooling phase. Whether this relaxes a borrowing constraint depends on whether the borrowing constraint is imposed, as in the "BC" treatment.

The second case, termed "Correlated Income and Ability", allows parents income to influence the child's ability. This dependence of ability on the transfer from parents is parameterized by $\theta_{\text {pinc }}$. For this treatment, an additional moment is added: the correlation between family income and the child's test score, denoted " $c(t, Y)$ " in Table 16 . The model links income to ability through $\theta_{\text {pinc }}$ and this is reflected in $c(t, Y)$. The parameter estimates are reported in Table 17.

In the initial block of moments in Table 16, in which the family influence is through resources only, the effect of family income is monotone and relatively small compared to the data. In particular, the estimated model in the $\mathrm{BC}$ case mimics very closely the influence of parent's income on education attainment for the higher quartiles but is unable to match the negative coefficients on the second quartile. The fit of the model is slightly better in the borrowing constraint (BC) case. The fit improves for every group but only by a small amount.

Once the family income influences ability as well, the results are somewhat different. First, the noise in the test score matters, particularly for the white and female sub-groups. Second, despite adding an additional moment, the fit of the model is better for the male, female and white groups compared to the case of no correlation between family income and ability. In this case, the simulated data does capture the positive correlation between income and the test score seen in the data through a positive estimate of the parameter $\theta_{\text {pinc }}$. Thus allowing family income to affect ability fits the data better for these groups. ${ }^{34}$ There is modest improvement with the borrowing constraint case, though none for the white and black groups treated separately. Again, this specification does not capture the

\footnotetext{
${ }^{32}$ This pattern is in contrast to the findings reported in Table 3 of Belley and Lochner (2007a) for college attendance in the NLSY97 as they find the coefficients are all positive.

${ }^{33}$ From simulation, the mean of $Z$ is 1.5 , the median is 1.26 and the fraction of zero transfers is about $5 \%$.

${ }^{34}$ This is consistent with the reduced form findings in Belley and Lochner (2007a) and Johnson (2013) where the regression coefficients on family income are lower when other family characteristics are included as covariates.
} 
non-monotone relationship between family income and educational attainment.

\subsection{Parent's Education}

This section studies the impact of parent's (throughout this is mother's) education on educational outcomes. ${ }^{35}$ This is taken as an alternative to a family link based on income or transfers alone. Importantly, for our sample the correlation between family income and mother's education is around 0.2 for the pooled sample and the sub-groups. Thus we are looking at a variation in the data different from the effects of family income.

\subsubsection{Additional Moments}

There are two avenues of influence explored. First, the parent's education impacts the tastes of the child. This is the case labeled "Correlated with Tastes" in the tables. Second, the parent's education impacts the ability of the child. This influence is measured by a correlation between parent's education and test score in the data. This is the case labeled "Correlated with Ability" in the following tables.

Specifically, to capture the influence of parent's education on outcomes, the mother's completion of high school or not, is treated as a dummy variable, denoted $p e_{i}$, in a version of (1):

$$
\operatorname{Pr}\left(e_{i}=1\right)=\frac{\exp ^{\alpha_{0}^{r}+\alpha_{1}^{r} a_{i}+\mu^{p} p e_{i}}}{1+\exp ^{\alpha_{0}^{r}+\alpha_{1}^{r} a_{i}+\mu^{p} p e_{i}}} .
$$

The estimates obtained from (23) are included in the moments to be matched.

In addition, for the "Correlated with Ability" model, the moments include the observed correlation between parent's education and the child's test score. There is no comparable moment for the "Correlated with Tastes" case as tastes are not directly observed, nor is a signal of them.

\subsubsection{Results}

The parameter estimates are given in Table 18 and the moments in Table 19 in blocks depending on the channel of influence. The parameters and moments are specific to the blocks.

The estimated parameter $\varepsilon_{p e}$ is the shift in the mean of the distribution of tastes if the mother attains a high school degree. The estimated parameter $\theta_{p e}$ captures the influence of mother's education on the mean of the distribution of ability. In the simulated data, mother's education is randomly drawn to match the group specific high school attainment rates. ${ }^{36}$

From the discussion of the baseline models, there were two key findings. The first was the estimate of no noise in the test score. The second was the slight improvement in fit with an occasionally binding borrowing constraint.

Neither of those conclusions survives these extensions of the model. Despite matching additional moments, both of these cases fit the moments, such as the college attainment rate, better than the baseline model and do so without borrowing constraints. This is particularly noteworthy relative to the specification in which the influence within the family arises through resource flows. Of these two cases, the "Correlated with Tastes" fits the data moments very closely.

\footnotetext{
${ }^{35}$ In keeping with the literature, including Belley and Lochner (2007a), the analysis isolates the effects of mother's education.

${ }^{36}$ These rates are 78.77 (all), 79.17 (male), 78.35 (female), 75.61 (black) and 88.61 (white).
} 
The models do fail in one important dimension: they do not create under-match. Interestingly, this is true for the specification with borrowing constraints: this source of under-match is not enough to improve the fit along the mismatch dimension.

Further, there is some evidence of noise in the test scores. Specifically, looking at indicated in Table 18, for both models of correlation and regardless of the imposition of a borrowing constraint, the estimate of $\sigma$ is much larger than the baseline estimate. ${ }^{37}$ The linking of parent's education to either tastes or ability limits the influence of these factors and thus enlarges the role played by noise in the test score for creating (measured) mismatch. This source of mismatch is unrelated to the efficient allocation of individuals to educational attainment. It is simply noise from the perspective of the researcher.

Note that the parameters that govern the influence of parent's education on tastes $\left(\varepsilon_{p e}\right)$ or ability $\left(\theta_{p e}\right)$ are positive. In the estimated model, an increase in mother's education either increases the taste for higher education or the ability of offspring.

The blocks labeled "No BC" and "BC" for each of the "correlated with taste" case are identical and this is the case for four of the five groups in the "correlated with ability" case, with the black sub-group being an exception. This indicates that no substantial improvement in fit was obtained by allowing an occasional borrowing constraint. The estimation of the "BC" case was conducted at numerous starting values for $\bar{b}$, searching for an improvement.

Looking at the moments in Table 19, the treatment allowing a correlation between parent's education and ability adds an additional moment from the data, the correlation between parent's education and test score. Note that the simulated model includes a link between parent's income and ability that, in part, helps to match this correlation. In the data, for all sub-groups, the correlation of test score and parents ability is positive. The estimated model reproduces these correlations quite well. As is clear from this table, the fit of this model is extremely good. While the model does not nest the baseline and has an additional parameter, the fit of the moments is better than the baseline.

Returning to the theme of mismatch, note that the estimated models in either the "correlated with tastes" or "correlated with ability" cases produce a substantial amount of over-match but no under-match is present. The models do a good job of matching the college rates.

\subsection{Parent's Education and Income}

If borrowing constraints are not a significant factor in the estimated model with parent's education influencing tastes and/or ability, then matching regression results, such as those reported in Belley and Lochner (2007a), in which both parent's income and education are significant is a challenge. This sub-section pursues that issue, with attention to the implications for mismatch as well.

This specification allows heterogeneity in both parent's income and education. As in the data, the correlation between these two attributes is set at 0.20 . The model allows parent's education to influence tastes and parent's income to relax the budget constraint. ${ }^{38}$

The moments, shown in Table 20, include a version of (22) supplemented to include parent's (mother's) education:

\footnotetext{
${ }^{37}$ The panel in Table 19 labeled "No Noise" shows how the fit deteriorates in a simulation using the estimated parameters for the case with $\sigma==0$.

${ }^{38}$ To isolate these two channels, neither influences ability.
} 


$$
\operatorname{Pr}\left(e_{i}=1\right)=\frac{\exp ^{\alpha_{0}^{r}+\alpha_{1}^{r} a_{i}+\mu^{p} p e_{i}+\mu_{2}^{r} i n c_{i}^{2}+\mu_{3}^{r} i n c_{i}^{3}+\mu_{4}^{r} i n c_{i}^{4}}}{1+\exp ^{\alpha_{0}^{r}+\alpha_{1}^{r} a_{i}+\mu^{p} p e_{i}+\mu_{2}^{r} i n c_{i}^{2}+\mu_{3}^{r} i n c_{i}^{3}+\mu_{4}^{r} i n c_{i}^{4}}} \cdot 39
$$

As shown in Table 20 by a "*”, the coefficient on parent's education, $\mu^{p}$, was significantly different from zero for all groups while the income coefficients were often insignificant in the data moments. As before, the effect of the second quartile on the likelihood of a college education is negative, some are significant. The effects of the third quartile are insignificant for all groups.

The estimated model allows parents education to influence tastes, parameterized by $\varepsilon_{p e}$ and shown in Table 21 . As before, there is no comparable moment in the data as tastes are unmeasured.

The main results described in the case where parent's education influenced tastes in the absence of an effect of parent's income remain. There is no evidence of a borrowing constraint mattering: the "No BC" and "BC" cases are identical. Test scores remain noisy.

Despite the added moment associated with the inclusion of parent's education in (24), the model fits better than the specification with parent's income effects alone. Interestingly, the estimated model produces negative effects of parent's income on the likelihood of college for the second and third quartiles. This is induced by the correlation between parent's income and education, not through a borrowing constraint. As before, the model fails to produce sufficient under-match.

\footnotetext{
${ }^{39}$ Weaker results obtain when using a measure of wealth rather than family income. In keeping with the literature, such as Belley and Lochner (2007a), we focus on family income and not wealth.
} 
Table 16: Moments: Family Income

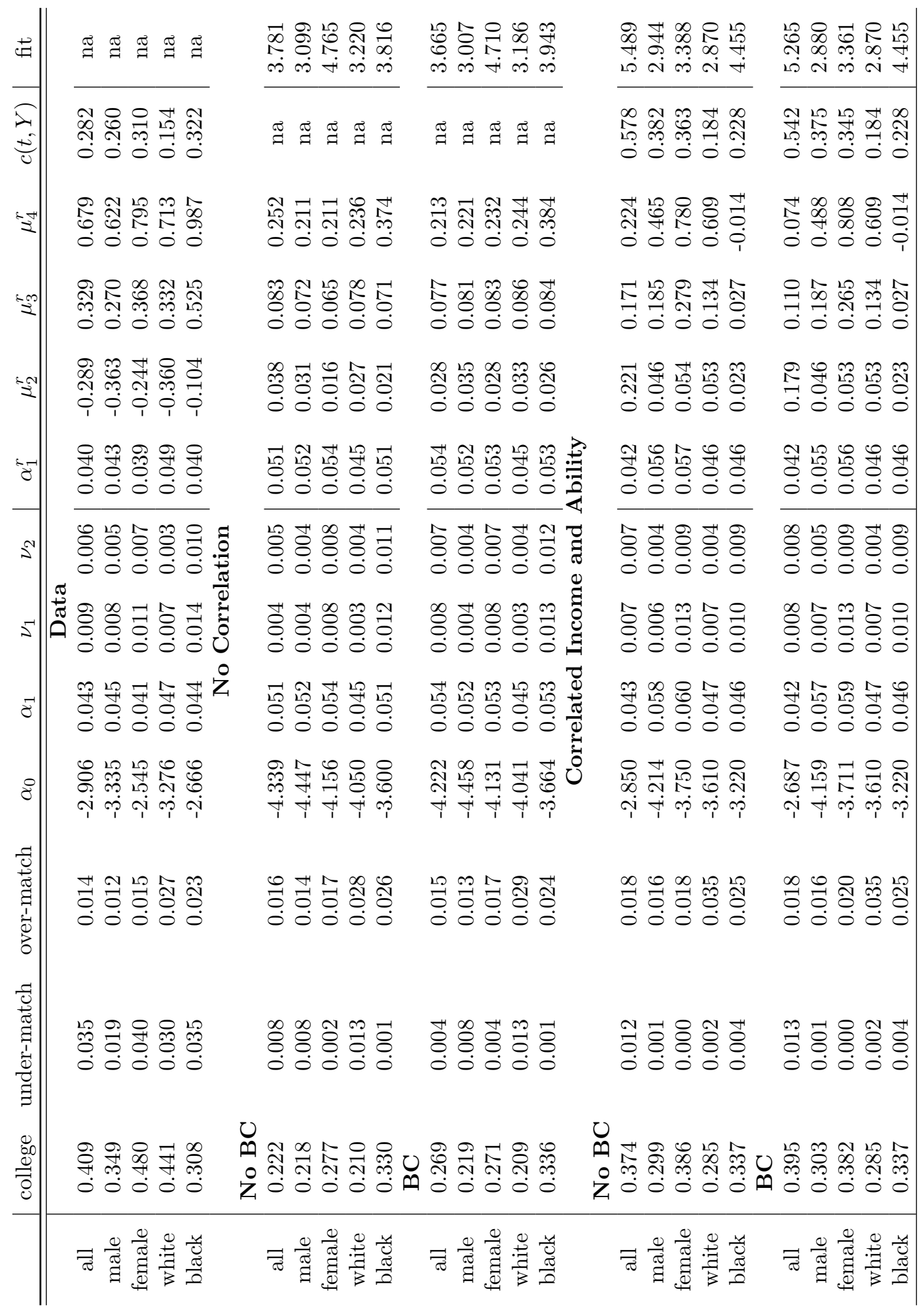


Table 17: Parameter Estimates: Family Income

\begin{tabular}{c|cccccc} 
& $\phi$ & $\bar{\varepsilon}$ & $\sigma$ & $h(\bar{e})$ & $\theta_{\text {pinc }}$ & $\bar{b}$ \\
\hline \hline & \multicolumn{7}{|c}{ No Correlation } \\
all & 1.732 & 24.848 & 0.000 & 0.339 & na & na \\
male & 1.834 & 23.769 & 0.000 & 0.360 & na & na \\
female & 1.401 & 24.821 & 0.004 & 0.344 & na & na \\
white & 1.981 & 24.407 & 0.067 & 0.359 & na & na \\
black & 1.204 & 24.780 & 0.006 & 0.346 & na & na \\
& $\mathbf{B C}$ & & & & & \\
all & 1.422 & 24.900 & 0.012 & 0.341 & na & 0.005 \\
male & 1.822 & 23.614 & 0.003 & 0.362 & na & 0.001 \\
female & 1.431 & 24.793 & 0.004 & 0.344 & na & 0.023 \\
white & 1.965 & 24.514 & 0.077 & 0.356 & na & 0.013 \\
black & 1.180 & 24.239 & 0.041 & 0.352 & na & 0.098 \\
\hline & \multicolumn{7}{|c}{ Correlated Income and } & Ability \\
all & no BC & & & & & \\
male & 3.784 & 20.303 & 0.090 & 0.795 & 0.928 & na \\
female & 1.507 & 13.249 & 0.323 & 0.639 & 0.477 & na \\
white & 2.166 & 15.394 & 0.741 & 0.574 & 0.978 & na \\
black & 1.496 & 24.935 & 0.830 & 0.615 & 0.268 & na \\
& $\mathbf{B C}$ & & & & & \\
all & 2.991 & 21.181 & 0.036 & 0.757 & 0.866 & 0.204 \\
male & 2.350 & 13.846 & 0.365 & 0.620 & 0.512 & 1.438 \\
female & 1.540 & 15.303 & 0.779 & 0.570 & 0.899 & 1.433 \\
white & 2.166 & 10.004 & 0.830 & 0.615 & 0.268 & 14.238 \\
black & 1.496 & 24.935 & 0.000 & 0.428 & 0.254 & 9.995 \\
\hline
\end{tabular}

This table reports parameter estimates for a model in which family income influences educational attainment. 
Table 18: Parameter Estimates: Parent's Education

\begin{tabular}{|c|c|c|c|c|c|c|}
\hline & \multicolumn{6}{|c|}{ Correlated with Tastes } \\
\hline & $\begin{array}{c}\phi \\
\end{array}$ & $\bar{\varepsilon}$ & $\sigma$ & $h(\bar{e})$ & $\varepsilon_{p e}$ & $b$ \\
\hline all & 0.875 & 14.248 & 3.688 & 1.018 & 5.120 & na \\
\hline male & 0.911 & 17.838 & 3.584 & 0.870 & 3.389 & na \\
\hline female & 0.682 & 10.078 & 4.978 & 0.956 & 5.383 & na \\
\hline white & 0.678 & 5.043 & 4.403 & 0.820 & 5.361 & na \\
\hline black & \multicolumn{5}{|l|}{$\mathrm{BC}$} & na \\
\hline all & 0.876 & 14.291 & 3.682 & 1.019 & 5.126 & 8.089 \\
\hline male & 0.909 & 18.093 & 3.568 & 0.852 & 3.200 & 17.837 \\
\hline female & 0.690 & 10.259 & 4.972 & 0.955 & 5.457 & 6.627 \\
\hline white & 0.644 & 5.058 & 4.374 & 0.820 & 5.177 & 8.719 \\
\hline \multirow[t]{3}{*}{ black } & 1.195 & 14.968 & 4.210 & 1.054 & 5.667 & 11.408 \\
\hline & \multicolumn{6}{|c|}{ Correlated with Ability } \\
\hline & \multicolumn{5}{|c|}{ No BC } & $\bar{b}$ \\
\hline all & 1.983 & 10.015 & 0.815 & 1.738 & 0.192 & na \\
\hline male & 1.106 & 13.807 & 1.916 & 1.044 & 0.682 & na \\
\hline female & 0.799 & 8.982 & 3.513 & 1.030 & 0.502 & na \\
\hline white & 1.605 & 11.539 & 0.489 & 1.447 & 0.553 & na \\
\hline black & $\begin{array}{l}1.644 \\
\text { BC }\end{array}$ & 16.346 & 0.621 & 1.686 & 0.274 & na \\
\hline all & 1.983 & 10.016 & 0.814 & 1.738 & 0.192 & 0.955 \\
\hline male & 1.101 & 14.714 & 1.914 & 1.043 & 0.686 & 0.968 \\
\hline female & 0.799 & 9.297 & 3.511 & 1.031 & 0.500 & 1.127 \\
\hline white & 1.602 & 11.576 & 0.485 & 1.445 & 0.558 & 1.318 \\
\hline black & 2.346 & 16.564 & 0.795 & 1.764 & 0.155 & 0.152 \\
\hline
\end{tabular}

This table reports estimates for a model in which parent's education influences tastes or ability. 
Table 19: Moments: Parent's Education

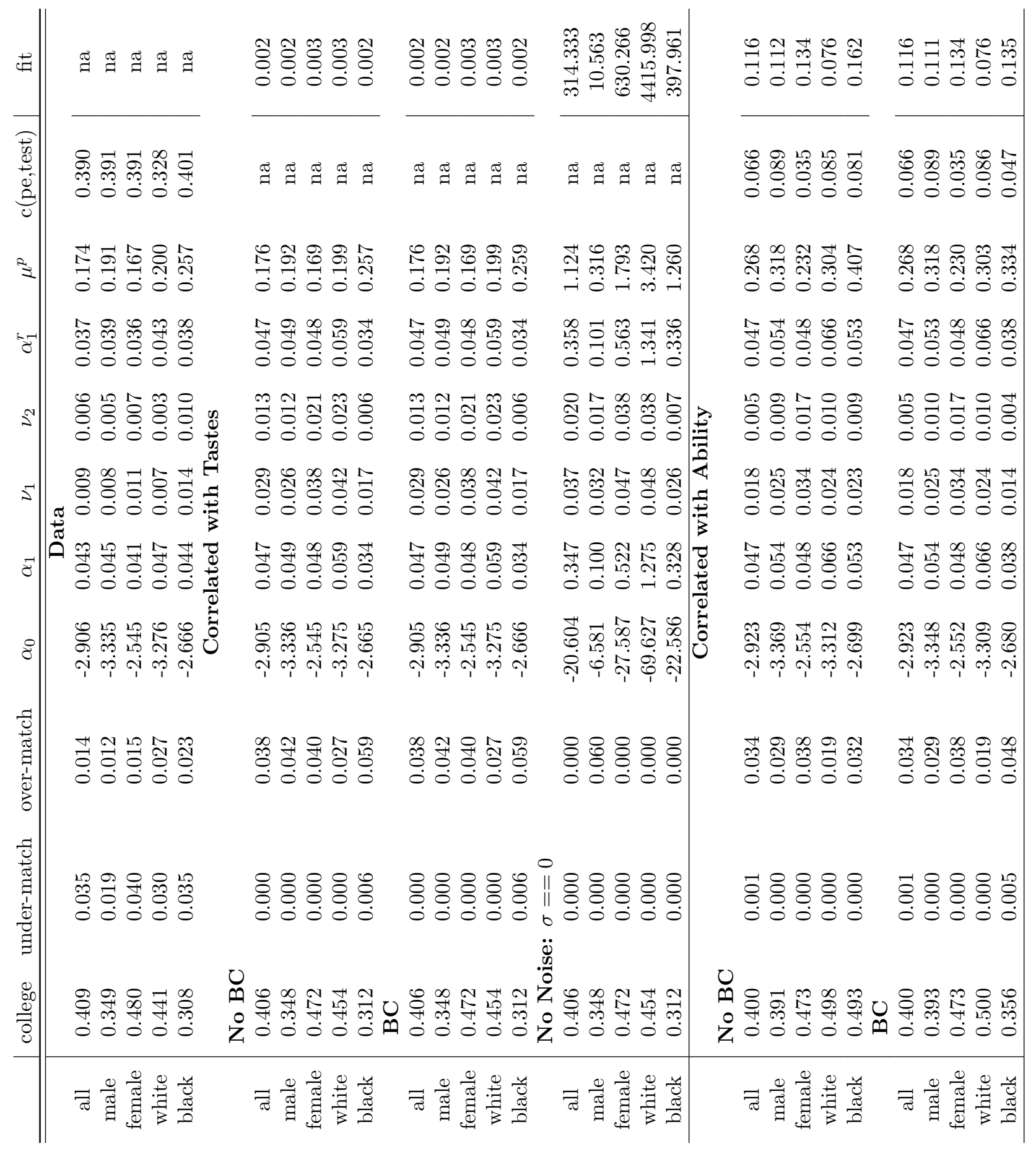


Table 20: Moments: Parent's Education and Family Income

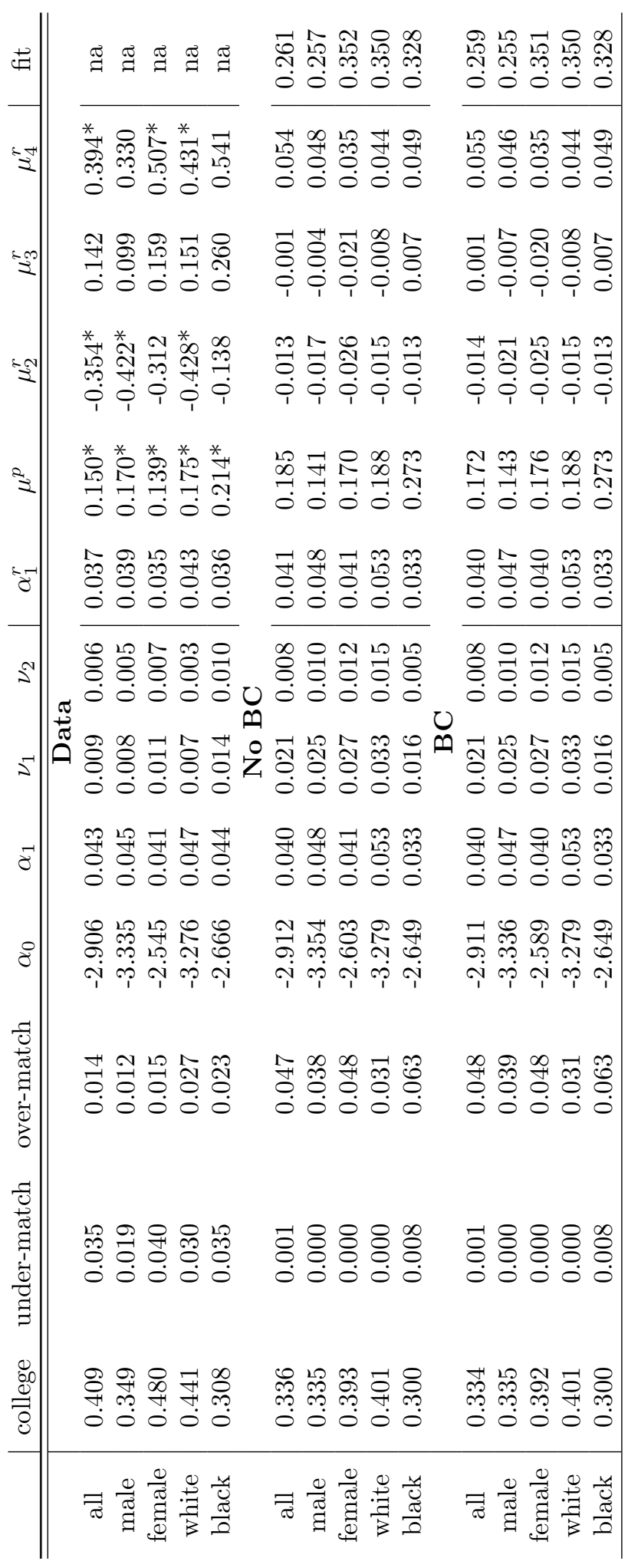


Table 21: Parameter Estimates: Parent's Education and Income

\begin{tabular}{|c|c|c|c|c|c|c|}
\hline & $\begin{array}{c}\phi \\
\text { No B B }\end{array}$ & $\bar{\varepsilon}$ & $\sigma$ & $h(\bar{e})$ & $\varepsilon_{p e}$ & $\bar{b}$ \\
\hline all & 1.070 & 15.389 & 3.806 & 1.016 & 4.725 & na \\
\hline male & 0.917 & 18.361 & 4.222 & 0.864 & 4.112 & na \\
\hline female & 0.871 & 10.766 & 4.987 & 0.961 & 5.147 & na \\
\hline white & 0.756 & 5.020 & 4.458 & 0.815 & 5.424 & na \\
\hline black & $\begin{array}{l}1.240 \\
\text { BC }\end{array}$ & 15.650 & 4.247 & 1.042 & 5.350 & na \\
\hline all & 1.063 & 16.377 & 3.905 & 1.006 & 4.530 & 20.00 \\
\hline male & 0.919 & 19.364 & 4.211 & 0.866 & 4.167 & 20.00 \\
\hline female & 0.876 & 10.828 & 4.996 & 0.963 & 5.308 & 20.00 \\
\hline white & 0.756 & 5.020 & 4.458 & 0.815 & 5.424 & 20.00 \\
\hline black & 1.240 & 15.650 & 4.247 & 1.042 & 5.351 & 20.00 \\
\hline
\end{tabular}

This table reports estimates for a model in which parent's education influences tastes and parent's income can relax a budget constraint. 


\section{Conclusion}

This paper studies the determinants of mismatch using the NLSY97 sample. It does so through two approaches. One that ignores the influence of family income and education and another in which these factors are apparent.

There are a couple of key findings from the initial analysis. First, mismatch is largely a consequence of variations in tastes for education rather than noise in the test score. Second, a model with occasionally binding (estimated) borrowing constraints fits the data slightly better than a model without capital market frictions.

Once the influence of parents, either through the relaxation of a budget constraint or through the impact of mother's education on tastes and/or ability, is introduced the results change. The influence of parents arises largely through the impact of mother's education rather than by relaxing a binding borrowing constraint. That is, once parent's education is taken into account, there is no evidence of a binding borrowing constraint. In this case, the mismatch arises from variations in tastes and, in contrast to the results without family influences, noise in test scores.

There is an open issue, unresolved within the model, about the implications of mismatch arising from taste shocks. At one extreme, tastes represent exogenous influences on the choice of an agent. From this perspective, the optimal allocation conditions jointly on tastes and ability and the resulting assignment to educational attainment is efficient. Measured mismatch reflects the neglect of tastes in determining education choice and is not a measure of inefficiency.

At the other extreme, tastes themselves may reflect social interactions. Put differently, taste differences may reflect social capital accumulation influenced by peers. ${ }^{40}$ Someone with very high ability brought up in a setting where college attainment is not highly valued may choose not to attend college. In this case, an efficient allocation might indeed assign that person to a higher level of education attainment to avoid the loss of an under-match.

One natural extension of the analysis is, as in Dillon and Smith (2013), to consider variations in college quality as another dimension of mismatch. In this case, mismatch may arise from the assignment of low (high) ability individuals to high (low) quality schools.

Another extension is to consider mismatch in both labor markets and in educational attainment. The model abstracts from labor market frictions. Their interaction with education decisions remains an open issue.

\footnotetext{
${ }^{40}$ See Durlauf and Fafchamps (2006) and the references therein for models along these lines.
} 


\section{Appendix}

\subsection{Data}

Here is a detailed list of variables used from the NLSY97 and NLSY79 panels.

For the NLSY97

- ASVAB Score: R9829600 ASVAB MATH VERBAL SCORE PCT 1999

- Wage:T8976700 YINC 17002013 TOTAL INCOME FROM WAGES AND SALARY IN PAST YEAR

- Educational attainment: T8129000 CV HGC 13142013 HIGHEST GRADE COMPLETED PRIOR TO THE 13/14 ACAD YEAR

- Mother's Education: biomumedu, R1302500 CV HGC BIO MOM 1997 BIOLOGICAL MOTHERS HIGHEST GRADE COMPLETED

- Parent's income: parentinc97, R2563300 CV INCOME GROSS YR 1998 GROSS HH INCOME IN PAST YEAR

For NLSY79:

- sample id: r0173600 SAMPLE ID 1979 SAMPLE IDENTIFICATION CODE

- rosen80:r0304410 ROSENBERG SCORE 1980 SELF-ESTEEM SCORE

- degree12:t3214200 Q3 10D 2012 HIGHEST DEGREE EVER RECEIVED

- rotter:r0153710 ROTTER SCORE 1979

- asveb3:r0618301 AFQT 31981 PROFILES, ARMED FORCES QUALIFICATION TEST (AFQT) PERCENTILE SCORE -

- 4915800 Q13 5 TRUNC 2014 TOTAL INCOME FROM WAGES AND SALARY IN PAST CALENDAR YEAR (TRUNC)

- hgc91:r3656901 HGC REV91 1991 HIGHEST GRADE COMPLETED AS OF MAY 1 SURVEY YEAR (REVISED)

- hourwage30:r3523500 CPSHRP 1991 HOURLY RATE OF PAY CURRENT/MOST RECENT JOB (survey year 1991) 


\subsection{Additional Results}

This sub-section reports additional results: counterfactuals and robustness.

\subsubsection{Counterfactuals}

\subsubsection{Robustness}

This section presents three robustness exercises: (i) increased risk aversion, (ii) increase tuition by $20 \%$ and (iii) using a weighting matrix. The parameter estimates and moments are reported below. 
Table 22: Moments: Comparing Groups

\begin{tabular}{|c|c|c|c|c|c|c|c|c|}
\hline & college & under-match & over-match & $\alpha_{0}$ & $\alpha_{1}$ & $\nu_{1}$ & $\nu_{2}$ & fit \\
\hline \multicolumn{9}{|c|}{$\overline{\text { Baseline }}$} \\
\hline all & 0.253 & 0.009 & 0.016 & -3.989 & 0.049 & 0.008 & 0.006 & 0.889 \\
\hline male & 0.227 & 0.012 & 0.014 & -4.196 & 0.050 & 0.007 & 0.005 & 0.364 \\
\hline female & 0.302 & 0.005 & 0.020 & -3.663 & 0.049 & 0.010 & 0.008 & 1.268 \\
\hline white & 0.248 & 0.015 & 0.031 & -3.565 & 0.042 & 0.006 & 0.003 & 0.515 \\
\hline black & 0.291 & 0.008 & 0.026 & -3.531 & 0.046 & 0.011 & 0.009 & 0.786 \\
\hline low SES & 0.229 & 0.012 & 0.018 & -4.074 & 0.048 & 0.007 & 0.005 & 0.575 \\
\hline high SES & 0.273 & 0.020 & 0.048 & -3.016 & 0.036 & 0.007 & 0.006 & 0.631 \\
\hline \multicolumn{9}{|c|}{ Same Ability } \\
\hline male & 0.251 & 0.007 & 0.013 & -4.184 & 0.052 & 0.009 & 0.006 & 0.571 \\
\hline female & 0.318 & 0.003 & 0.017 & -3.758 & 0.052 & 0.011 & 0.008 & 1.311 \\
\hline white & 0.387 & 0.000 & 0.019 & -3.508 & 0.056 & 0.015 & 0.010 & 6.998 \\
\hline black & 0.241 & 0.018 & 0.033 & -3.499 & 0.040 & 0.006 & 0.006 & 1.077 \\
\hline low SES & 0.252 & 0.010 & 0.017 & -3.941 & 0.048 & 0.007 & 0.006 & 0.598 \\
\hline high SES & 0.319 & 0.012 & 0.042 & -2.958 & 0.040 & 0.010 & 0.008 & 0.859 \\
\hline \multicolumn{9}{|c|}{ Same Tastes } \\
\hline male & 0.252 & 0.017 & 0.038 & -3.371 & 0.040 & 0.007 & 0.006 & 4.402 \\
\hline female & 0.339 & 0.016 & 0.055 & -2.578 & 0.035 & 0.009 & 0.008 & 7.912 \\
\hline white & 0.346 & 0.058 & 0.111 & -1.621 & 0.019 & 0.005 & 0.005 & 11.243 \\
\hline black & 0.256 & 0.002 & 0.000 & -5.198 & 0.067 & 0.011 & 0.007 & 3.243 \\
\hline low SES & 0.238 & 0.011 & 0.014 & -4.114 & 0.049 & 0.006 & 0.005 & 0.639 \\
\hline \multicolumn{8}{|c|}{ Same $h(\bar{e})$} & 0.602 \\
\hline male & 0.181 & 0.008 & 0.000 & -5.775 & 0.066 & 0.005 & 0.003 & 2.619 \\
\hline female & 0.208 & 0.003 & 0.002 & -5.688 & 0.068 & 0.006 & 0.004 & 4.324 \\
\hline white & 0.056 & 0.003 & 0.000 & -19.439 & 0.202 & 0.001 & 0.000 & 39.117 \\
\hline black & 0.339 & 0.010 & 0.045 & -2.834 & 0.039 & 0.013 & 0.011 & 1.566 \\
\hline low SES & 0.245 & 0.012 & 0.020 & -3.872 & 0.047 & 0.007 & 0.006 & 0.577 \\
\hline high SES & 0.237 & 0.016 & 0.058 & -3.419 & 0.039 & 0.006 & 0.005 & 1.192 \\
\hline \multicolumn{9}{|c|}{ Same borrowing limit } \\
\hline male & 0.263 & 0.010 & 0.023 & -3.712 & 0.046 & 0.007 & 0.006 & 1.047 \\
\hline female & 0.288 & 0.005 & 0.018 & -3.827 & 0.050 & 0.009 & 0.007 & 1.315 \\
\hline white & 0.269 & 0.015 & 0.037 & -3.289 & 0.040 & 0.005 & 0.004 & 0.626 \\
\hline black & 0.305 & 0.009 & 0.051 & -3.168 & 0.042 & 0.011 & 0.010 & 2.227 \\
\hline low SES & 0.241 & 0.012 & 0.018 & -3.961 & 0.048 & 0.006 & 0.005 & 0.557 \\
\hline high SES & 0.282 & 0.020 & 0.049 & -2.937 & 0.036 & 0.007 & 0.006 & 0.616 \\
\hline
\end{tabular}

This table reports moments with some parameters held constant across the groups. There is no re-estimation of other parameters. These moments are for the borrowing constraint case. 
Table 23: Parameter Estimates: Robustness

\begin{tabular}{|c|c|c|c|c|c|}
\hline & $\phi$ & $\bar{\varepsilon}$ & $\sigma$ & $h(\bar{e})$ & $\bar{b}$ \\
\hline & \multicolumn{5}{|c|}{ BC Baseline } \\
\hline all & 1.581 & 24.979 & 0.000 & 0.449 & 0.161 \\
\hline male & 1.582 & 26.171 & 0.001 & 0.423 & 0.048 \\
\hline female & 1.555 & 22.639 & 0 & 0.520 & 0.241 \\
\hline white & 2.930 & 14.512 & 0.002 & 0.843 & 0.006 \\
\hline black & 1.303 & 28.258 & 0.019 & 0.411 & 0.133 \\
\hline low SES & 1.617 & 25.553 & 0.004 & 0.452 & 0.000 \\
\hline \multirow[t]{2}{*}{ high SES } & 1.785 & 24.982 & 0.004 & 0.546 & 0.011 \\
\hline & \multicolumn{5}{|c|}{ Increased Risk Aversion: $\gamma=2$} \\
\hline all & 1.626 & 27.213 & 0.013 & 0.510 & 19.993 \\
\hline male & 1.969 & 20.821 & 0.048 & 0.586 & 20.000 \\
\hline female & 1.562 & 23.910 & 0.051 & 0.550 & 0.392 \\
\hline white & 2.786 & 18.070 & 0.010 & 0.661 & 20.000 \\
\hline black & 1.293 & 9.290 & 1.297 & 0.564 & 19.998 \\
\hline low SES & 1.642 & 29.259 & 0.066 & 0.479 & 19.950 \\
\hline \multirow[t]{2}{*}{ high SES } & 1.818 & 28.358 & 0.006 & 0.543 & 20.000 \\
\hline & \multicolumn{5}{|c|}{ Higher Tuition } \\
\hline all & 1.590 & 25.445 & 0.000 & 0.395 & 0.602 \\
\hline male & 1.814 & 22.556 & 0.004 & 0.556 & 0.007 \\
\hline female & 1.723 & 19.636 & 0.007 & 0.607 & 0.346 \\
\hline white & 2.757 & 15.972 & 0.002 & 0.827 & 0.016 \\
\hline black & 1.243 & 29.906 & 0.001 & 0.400 & 0.162 \\
\hline low SES & 1.639 & 26.327 & 0.006 & 0.382 & 0.590 \\
\hline \multirow[t]{2}{*}{ high SES } & 1.831 & 25.616 & 0.001 & 0.526 & 0.277 \\
\hline & \multicolumn{5}{|c|}{ Weighting Matrix } \\
\hline all & 1.975 & 16.277 & 0.030 & 0.645 & 17.394 \\
\hline male & 2.067 & 16.824 & 0.007 & 0.595 & 20.000 \\
\hline female & 2.394 & 11.152 & 0.000 & 0.817 & 20.000 \\
\hline white & 4.422 & 6.491 & 0.000 & 0.951 & 20.000 \\
\hline black & 1.223 & 29.973 & 0.007 & 0.342 & 20.000 \\
\hline low SES & 1.745 & 23.903 & 0.000 & 0.451 & 19.997 \\
\hline high SES & 3.370 & 8.758 & 0.001 & 0.924 & 20.000 \\
\hline
\end{tabular}

This table reports parameter estimates for the robustness exercises. 
Table 24: Moments: Robustness

\begin{tabular}{|c|c|c|c|c|c|c|c|c|}
\hline & college & under-match & over-match & $\alpha_{0}$ & $\alpha_{1}$ & $\nu_{1}$ & $\nu_{2}$ & fit \\
\hline \multicolumn{9}{|c|}{ Data } \\
\hline all & 0.409 & 0.035 & 0.014 & -2.906 & 0.043 & 0.009 & 0.006 & na \\
\hline male & 0.349 & 0.019 & 0.012 & -3.335 & 0.045 & 0.008 & 0.005 & na \\
\hline female & 0.480 & 0.040 & 0.015 & -2.545 & 0.041 & 0.011 & 0.007 & na \\
\hline white & 0.441 & 0.030 & 0.027 & -3.276 & 0.047 & 0.007 & 0.003 & na \\
\hline black & 0.308 & 0.035 & 0.023 & -2.666 & 0.044 & 0.014 & 0.010 & na \\
\hline low SES & 0.300 & 0.029 & 0.015 & -3.157 & 0.041 & 0.009 & 0.006 & na \\
\hline high SES & 0.502 & 0.044 & 0.038 & -2.502 & 0.041 & 0.008 & 0.006 & na \\
\hline \multicolumn{9}{|c|}{ Baseline BC } \\
\hline all & 0.253 & 0.009 & 0.016 & -3.989 & 0.049 & 0.008 & 0.006 & 0.889 \\
\hline male & 0.227 & 0.012 & 0.014 & -4.196 & 0.050 & 0.007 & 0.005 & 0.364 \\
\hline female & 0.302 & 0.005 & 0.020 & -3.663 & 0.049 & 0.010 & 0.008 & 1.268 \\
\hline white & 0.248 & 0.015 & 0.031 & -3.565 & 0.042 & 0.006 & 0.003 & 0.515 \\
\hline black & 0.291 & 0.008 & 0.026 & -3.531 & 0.046 & 0.011 & 0.009 & 0.786 \\
\hline low SES & 0.229 & 0.012 & 0.018 & -4.074 & 0.048 & 0.007 & 0.005 & 0.575 \\
\hline high SES & 0.273 & 0.020 & 0.048 & -3.016 & 0.036 & 0.007 & 0.006 & 0.631 \\
\hline \multicolumn{9}{|c|}{ Higher Risk Aversion: $\gamma=2$} \\
\hline all & 0.328 & 0.028 & 0.014 & -3.174 & 0.044 & 0.008 & 0.007 & 0.119 \\
\hline male & 0.321 & 0.019 & 0.012 & -3.490 & 0.048 & 0.007 & 0.006 & 0.029 \\
\hline female & 0.358 & 0.022 & 0.015 & -3.129 & 0.046 & 0.010 & 0.008 & 0.371 \\
\hline white & 0.303 & 0.025 & 0.027 & -3.127 & 0.041 & 0.005 & 0.004 & 0.300 \\
\hline black & 0.378 & 0.000 & 0.029 & -3.505 & 0.055 & 0.015 & 0.009 & 1.300 \\
\hline low SES & 0.306 & 0.030 & 0.015 & -3.325 & 0.044 & 0.007 & 0.006 & 0.064 \\
\hline high SES & 0.345 & 0.038 & 0.039 & -2.542 & 0.035 & 0.007 & 0.007 & 0.165 \\
\hline \multicolumn{9}{|c|}{ Higher Tuition } \\
\hline all & 0.253 & 0.009 & 0.016 & -3.910 & 0.048 & 0.006 & 0.006 & 0.914 \\
\hline male & 0.226 & 0.012 & 0.014 & -4.216 & 0.050 & 0.007 & 0.005 & 0.398 \\
\hline female & 0.316 & 0.004 & 0.018 & -3.687 & 0.051 & 0.010 & 0.007 & 1.269 \\
\hline white & 0.241 & 0.016 & 0.031 & -3.579 & 0.042 & 0.006 & 0.003 & 0.494 \\
\hline black & 0.296 & 0.008 & 0.027 & -3.459 & 0.045 & 0.011 & 0.010 & 0.740 \\
\hline low SES & 0.242 & 0.012 & 0.018 & -3.858 & 0.046 & 0.006 & 0.006 & 0.602 \\
\hline high SES & 0.287 & 0.020 & 0.046 & -2.952 & 0.036 & 0.007 & 0.006 & 0.583 \\
\hline \multicolumn{9}{|c|}{ Weighting Matrix } \\
\hline all & 0.392 & 0.000 & 0.032 & -3.087 & 0.049 & 0.010 & 0.008 & 158.267 \\
\hline male & 0.335 & 0.001 & 0.021 & -3.615 & 0.052 & 0.008 & 0.007 & 55.727 \\
\hline female & 0.474 & 0.000 & 0.033 & -2.732 & 0.052 & 0.010 & 0.009 & 147.861 \\
\hline white & 0.434 & 0.000 & 0.029 & -2.972 & 0.052 & 0.006 & 0.004 & 50.117 \\
\hline black & 0.326 & 0.002 & 0.028 & -3.482 & 0.049 & 0.011 & 0.011 & 84.847 \\
\hline low SES & 0.302 & 0.006 & 0.032 & -3.408 & 0.045 & 0.007 & 0.007 & 105.792 \\
\hline high SES & 0.493 & 0.000 & 0.044 & -2.313 & 0.046 & 0.008 & 0.006 & 95.532 \\
\hline
\end{tabular}

This table reports data and simulated moments for the estimated models for the robustness exercise. 


\section{References}

Adda, J., AND R. CoOper (2003): Dynamic economics: quantitative methods and applications. The MIT Press.

Belley, P., And L. Lochner (2007a): "The Changing Role of Family Income and Ability in Determining Educational Achievement," Journal of Human Capital, 1(1), 37-89.

(2007b): "The changing role of family income and ability in determining educational achievement," Working Paper 13527, National Bureau of Economic Research.

Bowen, W. G., AND D. BoK (1998): The shape of the river: Long-term consequences of considering race in college and university admissions. Princeton University Press.

Cameron, S. V., And J. J. Heckman (2001): "The dynamics of educational attainment for black, hispanic, and white males," Journal of political Economy, 109(3), 455-499.

Carneiro, P., And J. J. Heckman (2002): "The evidence on credit constraints in post-secondary schooling," The Economic Journal, 112(482), 705-734.

Cawley, J., K. Conneely, J. Heckman, and E. Vytlacil (1997): "Cognitive ability, wages, and meritocracy," in Intelligence, genes, and success, pp. 179-192. Springer.

Cawley, J., J. Heckman, And E. Vytlacil (2001): "Three observations on wages and measured cognitive ability," Labour Economics, 8(4), 419-442.

Cooper, R., And H. LiU (2016): "MisMatch in Human Capital Accumulation," Working Paper 22010, National Bureau of Economic Research.

Cooper, R., And G. Zhu (2015): "Household finance over the life-cycle: What does education contribute?," Review of Economic Dynamics, 20, 63-89.

Cunha, F., J. J. Heckman, And S. M. Schennach (2010): "Estimating the technology of cognitive and noncognitive skill formation," Econometrica, 78(3), 883-931.

Dillon, E. W., AND J. A. Smith (2013): "The determinants of mismatch between students and colleges," Discussion paper, National Bureau of Economic Research.

Durlauf, S., And M. Fafchamps (2006): "Social Capital," in Handbook of Economic Growth, pp. 1640-1699. North Holland.

FANG, H. (2006): "Disentangling the college wage premium: Estimating a model with endogenous education choices," International Economic Review, 47(4), 1151-1185.

Glomm, G., and B. Ravikumar (1992): "Public versus private investment in human capital: endogenous growth and income inequality," Journal of political economy, pp. 818-834.

Hanushek, E. A., G. Schwerdt, S. Wiederhold, and L. Woessmann (2015): "Returns to Skills around the World: Evidence from PIAAC," European Economic Review, 73, 103-130.

Heckman, J. J., J. Stixrud, And S. Urzua (2006): "The effects of cognitive and noncognitive abilities on labor market outcomes and social behavior," Journal of Labor economics, 24(3), 411-482.

Johnson, M. T. (2013): "Borrowing constraints, college enrollment, and delayed entry," Journal of Labor Economics, 31(4), 669-725.

Keane, M. P., AND K. I. Wolpin (2001): "The effect of parental transfers and borrowing constraints on educational attainment," International Economic Review, 42(4), 1051-1103. 
Lochner, L. J., And A. Monge-Naranjo (2011): "The Nature of Credit Constraints and Human Capital," American Economic Review, 101(6), 2487-2529.

Smith, J., M. Pender, And J. Howell (2013): "The full extent of student-college academic undermatch," Economics of Education Review, 32, 247-261. 